\title{
La nupcialidad en Buenos Aires a mediados del siglo XX: Chascomús, La Plata y San Martín
}

\author{
Viviana Masciadri
}

\author{
Consejo de Investigaciones Cientificas y Técnicas \\ Universidad de Buenos Aires
}

\section{Resumen}

Esta investigación analiza las tendencias en la nupcialidad tomando como hitos temporales 1947 y 1960 en Buenos Aires y tres partidos bonaerenses. En primera instancia se describe la política demográfica relacionada con la nupcialidad. Seguidamente se analizan las estadísticas de matrimonios y la estructura de la población por sexo, edad y por estado civil según la definición censal. Se describe además a la subpoblación que se desvinculó voluntariamente de una cohabitación o de un matrimonio atendiendo a la distribución relativa así como, a la probabilidad de estar divorciado en 1947 y separado/divorciado en 1960. Esta perspectiva transversal da contexto a las tendencias halladas en la constitución y disolución de las uniones. El trabajo concluye que la secularización no se había completado en la Argentina a mediados del siglo xx, de hecho, la política demográfica de entonces pretendió que la nupcialidad fuera la expresión de la política económica acuñada en el orden natural de las cosas.

Palabras clave: Nupcialidad, mediados del siglo veinte, políticas de población, Argentina.

\section{Abstract}

The nuptiality in Buenos Aires in the mid-twentieth century: Chascomus, La Plata and San Martin

This research analyzes nuptiality trends around 1947 and 1960 in Buenos Aires (Argentina) and three of bonaerenses districts. First this research describes the demographic policies related to nuptiality. Then the study analyzes the statistics of marriages and the structure of the population by sex, age and marital status according to the census definition. It also describes the subpopulation that voluntarily disassociated from a cohabitation or marriage based on the relative distribution as well as the probability of being divorced in 1947 and separated / divorced in 1960. This cross-cutting perspective contextualizes the trends in the constitution and dissolution of unions. The paper concludes that secularization had not been completed in the mid-twentieth century; in fact, the demographic policies demanded that the nuptiality was the expression of economic policies founded on the natural order of things.

Key words: Nuptiality, mid-twentieth century, population policies, Argentina. 


\section{INTRODUCCIÓN}

unque no existe una definición universal se entiende por políti-
cas de población, el conjunto de decisiones que conforman una
estrategia del sector público: "de acuerdo con las necesidades y aspiraciones de la colectividad para desarrollar, conservar y utilizar los recursos humanos que influyen sobre la migración y el crecimiento probable de la población, su distribución por edades, la constitución de la familia, la localización geográfica de los habitantes y la incorporación a la fuerza de trabajo y a la educación" (IUSSP y CELADE, 1982: 140) entre otros aspectos a destacar.

De modo que examinar lo que aconteció en materia de población en los años próximos a la sanción de la ley 14.394 de 1954 representa un hecho clave para comprender además, los alcances de las políticas de población que procuraron resolver el conflicto social que significó la inexistencia del divorcio vincular para las parejas de la época. En otros términos se podría interpretar que, el cambio legislativo aludido procuró un cambio de costumbre que indica un cambio más amplio en la sociedad como un todo (Elias, 1998: 218) generando resistencias.

En síntesis, el propósito de esta investigación es realizar una aproximación a las tendencias en la nupcialidad tomando como hitos temporales 1947 y 1960. El foco está puesto en los partidos bonaerenses de Chascomús, La Plata y San Martín a fin de mostrar ciertos aspectos de la nupcialidad que pueden ser descriptos mediante datos disponibles a escala departamental.

Luego de los aspectos conceptuales y metodológicos se abordan algunos elementos sobre política demográfica y nupcialidad que introducen el análisis de estadísticas referentes a matrimonios. Como la cifra de personas en edades casaderas incide en las primeras nupcias se describe, la estructura por sexo y edad de la población bonaerense destacando peculiaridades de los partidos seleccionados para realizar luego, la descripción de los datos censales vinculados con la variable estado civil que permitieron determinar el volumen de la población que se desvinculó voluntariamente de una unión consensual o de un matrimonio y la probabilidad de estar divorciado en 1947 y 1960. En último término se presenta la conclusión. 


\section{Aspectos ConCePtuales y Metodológicos}

\section{Según el Diccionario Demográfico Multilingüe,}

el estudio de la nupcialidad comprende, principalmente, el de los fenómenos cuantitativos que resultan de la existencia de matrimonios o uniones legítimas, es decir, de uniones entre personas de diferente sexo, realizadas en la forma prevista por la ley o por la costumbre y que confieren a las personas involucradas determinados derechos y obligaciones (IUSSP y CELADE, 1982: 83).

El análisis de la frecuencia de tales acontecimientos y de la disolución de los mismos proporciona la base para los estudios sobre nupcialidad. ${ }^{1}$ Además, si se atiende al sentido estricto del término nupcialidad, las nociones son endogamia, exogamia, matrimonios mixtos, homogamia y heterogamia.

Si bien en demografía, el estudio de la nupcialidad abarca los aspectos cuantitativos del fenómeno se advierte que, los términos de la definición exceden ${ }^{2}$ dicha definición pues históricamente la nupcialidad es en sí misma, la expresión de una determinada política.

Es sabido que en demografía se distinguen las políticas poblacionistas, de las políticas controlistas y, las natalistas o pronatalistas de las antinatalistas (IUSSP y CELADE, 1982: 140); por extensión existen las políticas favorables al divorcio o divorcistas y contrarias al mismo o antidivorcistas. Además, las doctrinas demográficas pueden eventualmente servir de base para la adopción de una política demográfica que no siempre se expresa como tal.

\footnotetext{
${ }^{1}$ Los estudios sobre nupcialidad abarcan una amplia indagación sobre el tópico constitución y disolución de las uniones conyugales y comprende, por extensión, el campo de los estudios sobre familias.

${ }^{2}$ Cierto, si la comprensión es en materia de matrimonio aparecen términos como Estado, autoridades eclesiásticas, formalidades administrativas, tradiciones, sociedades, tipo de unión (consensual, conyugal y libre), estabilidad, temporalidad. Cuando aparece la figura del divorcio, simultáneamente, en algunas legislaciones, se advierte la existencia de impedimentos para la disolución del vínculo matrimonial, con el aditivo de que la terminología técnica designa con la palabra pareja, "al conjunto de dos individuos de distinto sexo que viven en una unión estable" (IUSSP y CELADE, 1982: 83-84). Con todo, hoy es posible afirmar que una pareja es el conjunto de dos individuos no necesariamente de distinto sexo que viven en una unión temporal. Siendo que las parejas forman parte de la población, se las reconoce como sistemas cuasi invariantes, debido a que las características que las agrupan — que podrían remitir a las reglas de la homogamia y del patriarcado tomando como ejemplos la edad mínima al matrimonio, la diferencia de edad entre los cónyuges y la condición laboral según sexo- se han implantado más o menos definitivamente en el sistema social (Masciadri, 2012a). Aunque con el advenimiento de las sociedades industriales, con la urbanización y, sobre todo, con las modificaciones legislativas en materia de matrimonio se advierten cambios progresivos, pero lentos; la variación en el nivel de la esperanza de vida incide y se ha conjeturado que, en el futuro, se podrán adoptar carreras sucesivas y tener varios matrimonios con personas de diferentes generaciones (Bourgeois-Pichat, 1985: 87).
} 
De modo que esta investigación abordó en un primer momento, los aspectos vinculados a las políticas de población que dan sentido, a los datos poblacionales analizados pues se considera que ambos aspectos no deben desvincularse aunque no siempre sea posible abordarlos.

En materia de políticas de población se sabe que durante la segunda presidencia peronista, ${ }^{3}$ en el año 1954 se reformó el código civil (artículo 31 , ley 14.394) cuya letra dio lugar al divorcio vincular. Pero dicha ampliación en el derecho civil sucumbió ante el decreto-ley 4.070 del 1 de marzo de 1956 que la declaró en suspenso. El texto Demografia Argentina. Esbozo de una política demográfica representa la base para la comprensión de este hecho puntual, pues las modificaciones en materia de matrimonio influyen sobre las características y evolución de la nupcialidad de las poblaciones, al tiempo que responden a ellas (Domingo, 1997).

Sin embargo hay que notar que en este país, los cambios legislativos en materia de matrimonio no siempre se reflejaron en el registro estadístico. Tal dificultad tiene su expresión en términos de medición. Por ejemplo, un primer acercamiento al estudio de la nupcialidad se basa en la utilización de la tasa bruta de nupcialidad pues se sabe que ésta, medida en períodos largos, muestra un comportamiento constante en lo fundamental aunque perturbado por conflictos y crisis (Pressat, 1983: 179). Esta afirmación, cierta en términos generales evidencia dificultades de aplicación en contextos donde las parejas no necesariamente se formaban por la vía del matrimonio. Es el caso de los países centroamericanos y suramericanos donde, si bien prevalece la monogamia y la tradición católica, el matrimonio no es la única vía para la formación de las parejas ni tampoco el divorcio vincular es la única forma de desvinculación de las parejas (Masciadri, 2006).

Según observa Otero (2006: 50) "el conjunto de representaciones acerca de la realidad social implícitas en la construcción estadística y los criterios que las fundamentan permiten hablar de una ideología estadística que, como toda representación ideológica" está atravesada por juicios de valor. Desde esa perspectiva se podrían interpretar las lagunas estadísticas existentes sobre el tema. Sucede que la administración estadística formada en el paradigma ${ }^{4}$ invisibilizó a la población unida consensualmente hasta el V

\footnotetext{
${ }^{3}$ Del 4 de junio de 1952 al 20 de septiembre de 1955.

${ }^{4}$ El modelo occidental de matrimonio ancla su carácter de representación performativa en su rasgo monogámico, de pareja estable, favorable a la homogamia social y a la heterosexualidad obligatoria en tanto bisagra intergeneracional, fundado en la institución matrimonial que asegura la estabilidad personal y familiar y adverso a la institución del divorcio que genera inestabilidad personal y familiar (Masciadri, 2013).
} 
Censo Nacional de $1960 .{ }^{5}$ Y determinó también que, aunque la legislación argentina admitía el divorcio relativo desde 1889 se desconociera el volumen de la población divorciada hasta el IV Censo de 1947, situación que tuvo implicancias en las estadísticas de matrimonios que no registraron ningún tipo de divorcio (relativo o vincular) pese a que existe información aislada del estado civil divorciado de migrantes y en los juzgados (Rodríguez Molas, 1984; Valobra y Giordano, 2013).

No obstante los problemas enunciados, las fuentes disponibles son válidas para la exploración de la temática. En relación con las estadísticas de matrimonios la dificultad principal es que se trata de datos fragmentarios resultando dificultoso conformar series, como se verá luego. Lo propio sucede con la información referida a matrimonios por estado civil y nacionalidad de los contrayentes, sobre estacionalidad y sobre nacimientos fuera del matrimonio.

En relación con los datos censales es preciso mencionar que la pregunta referida al estado civil de las personas censadas en 1947 y en 1960 adolece de problemas debido a que las categorías de la variable no son mutuamente excluyentes (Pantelides, 1984; Cacopardo, 1996; Masciadri, 2002): (a) en el Censo de 1947 las categorías de estado civil registradas fueron soltero, casado, viudo y divorciado; (b) en el Censo de 1960 las categorías de estado civil enumeradas fueron soltero, casado, viudo, separado o divorciado, y unión de hecho - persona soltera que convive con otra sin haber contraído matrimonio- ${ }^{6}{ }^{6}$

En síntesis, el censo de 1947 sobreestimó la población soltera aunque todas las categorías fueron afectadas por errores en la declaración del estado civil. Es el caso de la población divorciada que disminuye entre 1947 y 1960 debido, posiblemente, a que una porción de la población divorciada legalmente (divorcio relativo) se declaró separada y personas separadas (de unión de hecho o de matrimonio) sin mediar trámite judicial alguno podrían haberse incluido en ella.

\footnotetext{
${ }^{5}$ En la Argentina, este tipo de unión a la que se denominó 'ilegítima' existió con frecuencia variable dependiendo de la región (Llorens y Ávila, 1948; Somoza, 1971; Bunge, 1984; Pantelides, 1984; Germani, 1987; Torrado, 1993; Torrado, 2003; Moreno, 2007). Datos de la Tabla 1 muestran que, en los partidos seleccionados, la llamada 'ilegitimidad' fue inferior a la media provincial con algunas excepciones: Chascomús, en 1959; y General San Martín, en 1958 y 1960.

${ }^{6}$ En el censo de 1947 la pregunta se dirigió al universo completo mientras que en 1960 la pregunta se aplicó a las personas de 12 años y más. Hay que aludir que el censo de 1960 relevó la disolución de las uniones indagando el estado civil como sigue: viuda (persona que perdió su condición de casada por fallecimiento del cónyuge legal, aún cuando se encuentra en unión de hecho), separada (persona que no convive con su cónyuge legítimo ni integra unión de hecho), divorciada (persona separada legalmente con posibilidad de volver a casarse) mientras que el Censo de 1947 se refiere a la categoría viudo y divorciado sin especificaciones (Cacopardo, 1996: 356).
} 
Con todo, esta exploración aplicó la metodología de estudios anteriores (Masciadri, 2002). El análisis es transversal o de momento sobre la base de datos publicados en boletines estadísticos de la provincia de Buenos Aires por el Ministerio de Economía, Dirección de Estadística además de los referidos en publicaciones de la Dirección General de Estadísticas e Investigación, Ministerio de Hacienda, Econometría y Previsión del año 1947 y de datos censales.

\section{Política demográfica Y NUPCIALIDAd}

Aquí, interesa retomar algunos planteos de la coyuntura del periodo peronista que incidieron en la política demográfica referida a la nupcialidad. Éstos estuvieron influidos por el pensamiento católico conservador, particularmente en algunos de los planteos de gobierno de la primera etapa del peronismo, aunque conviviendo con otras líneas divergentes. Perfiles que cristalizaron sus ideas mediante reformas - Constitución (1949) y Código Civil (1954) — y, en lo específico conforme a modificar el Derecho de Familia pero que, la falta de consenso jaqueó mediante la suspensión del artículo 31 (Ley 14.394) luego de la revolución ${ }^{7}$ palaciega de 1955 —autodenominada revolución argentina- que destituyó al presidente electo Juan Perón.

En efecto, pasada la Primera Guerra Mundial, el carácter conservador del Estado argentino se expresó en ciertos ámbitos. En el ejército se manifestó por medio de la Doctrina de Defensa Nacional, esa noción de la guerra total o integral que fuera "trasladada como concepción organizadora al campo político" por el peronismo (Bernetti y Puiggrós, 1993: 58) y mediante la Doctrina de Seguridad Nacional contrapuesta a la anterior y que dominó a partir de 1955. También tuvo su manifestación en el Ministerio de Educación — con la participación de Oscar Ivanissevich fundamentalista católico e interventor en la Universidad de Buenos Aires desde el 30 de abril de 1946 hasta el 27 de mayo de 1949, Secretario de Educación y Ministro de Educación del primer y segundo gobierno peronista y durante el tercer periodo, durante la presidencia de Estela Martínez de Perón. Finalmente, se evidenció en la política demográfica a revisar mediante un texto colateral a la política propiamente tal.

\footnotetext{
${ }_{7}^{7}$ De acuerdo con Hannah Arendt (2008: 44-45), una revolución es más que una insurrección triunfante y no se puede identificar a ésta con cualquier golpe de Estado ni con una guerra civil. Los golpes de Estado y las revoluciones palaciegas deben comprenderse como fenómenos "mediante los cuales el poder cambia de manos de modo diverso" y donde "el cambio que supone está circunscrito a la esfera de gobierno".
} 
Es posible afirmar que la comunidad científica vinculada al quehacer demográfico de la época - supuestamente neutral- identificó las transgresiones al modelo occidental de matrimonio en la obra Demografia Argentina. Esbozo de una política demográfica redactada por el ingeniero Emilio Llorens y el doctor en Ciencias Económicas Carlos Correa Ávila. El primero fue profesor de Geografía Económica General en la Universidad de Buenos Aires y alumno del colegio del Salvador - como lo fue Alejandro Bunge autor de Una Nueva Argentina, Arturo M. Bas autor de El divorcio: cáncer de la sociedad y como lo fueron los seis hijos varones de Alejandro Bunge además de varios futuros colaboradores de la Revista de Economía Argentina. El segundo fue profesor de Geografía Política y Económica Argentina de la Universidad de La Plata y miembro, junto a Llorens, de la elite de funcionarios estatales — entre los más notables, se reconocen a Raúl Presbisch y a José Figuerola - que asesoró al gobierno militar encabezado por Edelmiro Farrell (1943); jefe de la Dirección de Estadística de la Secretaría de Industria y Comercio; tesorero del Instituto Alejandro Bunge de Investigaciones Económicas y Sociales; secretario de redacción de la Revista de Economía Argentina y demás (González Bollo, 2004; Biernat, 2007; Otero, 2007).

Editada en 1948 por la intervenida Facultad de Ciencias Económicas de la Universidad Nacional de Buenos Aires, la obra enunciaba:

Para contrarrestar el ambiente que el concepto materialista de la vida ha ido formando en descrédito de la dignidad de la familia (...) y que ha tenido su máxima expresión en la terrible campaña que el comunismo emprendiera contra la institución familiar (...) es necesario organizar una campaña nacional permanente destinada a devolver ante el concepto popular el prestigio que la institución familiar debe gozar (Llorens y Correa, 1948).

En dicha campaña, la escuela era identificada como un "permanente instrumento de propaganda tanto en los niños como en sus respectivos familiares" (Llorens y Correa, 1948: 71), apreciaciones hechas en el capítulo séptimo Medidas de fomento de la nupcialidad a propósito de la Propagación de los conceptos acerca de la dignidad de la familia y su valor social.

En efecto, Llorens y Correa Ávila — discípulos de Alejandro Bunge quien fuera fundador en 1918 de la Revista de Economía Argentina la que incidió, sin duda, en los desarrollos de la demografía argentina como disciplina - apelando a un discurso que sostenían fundado científicamente establecían la necesidad de fortalecer la vida familiar, al tiempo que proponían medidas tendientes a fomentar la nupcialidad y la natalidad, y a disminuir 
la mortalidad. Para "acrecentar la nupcialidad y asegurar la vida familiar" formularon cuatro principios:

i) afirmar el cristiano concepto de la indisolubilidad del matrimonio; ii) eliminar extravíos legales que demoran o impiden el matrimonio legítimo; iii) realizar una campaña destinada a impedir las uniones ilegítimas, reemplazándolas y estabilizándolas por el matrimonio legítimo; iv) facilitar la celebración de matrimonios tempranos y crear dificultades a la soltería" (Llorens y Correa Ávila, 1948: 65).

Por cierto, entre las Medidas de fomento de la nupcialidad se encuentran - aparte de la Propagación de los conceptos acerca de la dignidad de la familia y su valor social mencionada-, la Campaña contra las uniones ilegítimas, las Modificaciones al régimen jurídico, la Educación para la vida familiar, las Medidas de orden económico y la Defensa y dignificación de la mujer.

Según se expresa en el marco de la Campaña contra las uniones ilegítimas, tanto el Estado como las instituciones culturales y sociales deben "mostrar los inconvenientes y peligros individuales y sociales" del concubinato, por lo tanto, se debía facilitar la inscripción matrimonial — principalmente en las zonas rurales - tal como se preconizó en el "Plan de gobierno 1947-51" en cuya redacción Llorens y Correa Ávila (1948: 72, 141) colaboraron, a pedido de José Figuerola quien presidió el Plan desde la Secretaría Técnica de la Presidencia, en calidad de miembros del Instituto Alejandro Bunge de Investigaciones Económicas y Sociales (Biernat, 2013: 10).

En el apartado referido a las Modificaciones al régimen jurídico, los discípulos de Bunge referían que "teniendo en cuenta que la base de la cultura argentina es absolutamente cristiana y católica" conferían al Estado la función de "asegurar la institución familiar conservando el régimen de indisolubilidad legal del matrimonio" (Llorens y Correa Ávila, 1948: 72). Además, expresaban que la equiparación de los "hijos legítimos con los ilegítimos" fomentaría el desorden social, lo que debía evitarse (Llorens y Correa Ávila, 1948: 73). Por otra parte, creían necesaria la modificación del "régimen del certificado prenupcial" el que debía diferirse cuando era muy difícil o casi imposible de obtener por falta de asistencia médica. Con ello, se evitaba la traba para la celebración de matrimonios pues, de no ser así, dicha constancia se transformaría en "un incentivo al concubinato y consiguientemente a la ilegitimidad" (Llorens y Correa Ávila, 1948: 73). 
Las medidas para la Educación para la vida familiar y la Defensa y dignificación de la mujer se encuentran en diálogo puesto que el criterio de los académicos era que "naturalmente el hombre y la mujer se inclinan hacia la familia, como un perfeccionamiento necesario" (Llorens y Correa Ávila, 1948: 74). Y el rol del Estado, mediante la escuela y otros medios (radiotelefonía), era el de mostrar las funciones específicas: la instrucción de la mujer debía propender hacia "el cuidado del hogar, la crianza y la educación de los hijos, la administración de la economía familiar" (Llorens y Correa Ávila, 1948: 74). Es decir, la política demográfica debía “exaltar en el ambiente y en la práctica la dignidad de la mujer como esposa y como madre", expresando su desacuerdo con todas las medidas tendientes a la ampliación de derechos por parte de las mujeres: "a trabajar, a ganar un salario similar al del hombre, a intervenir activamente en política" (Llorens y Correa Ávila, 1948: 76) pues, con ello, se ponía en peligro la organización familiar.

En cuanto a las Medidas de orden económico, preconizaban la aplicación de un impuesto especial a los solteros, a fin de inducir al matrimonio y contribuir, asimismo, a solventar las ventajas sociales atribuibles a los casados tales como préstamos amortizados en escala ascendente por cada hijo, sobresueldo por matrimonio, entre otros. ${ }^{8}$

Como se sabe, en el periodo bajo estudio, tres normativas tuvieron relación — más o menos directa - con la nupcialidad. Una, es la primera ley de adopción (13.252) sancionada en 1948, durante el primer gobierno peronista. Esta ley establecía, entre otras cuestiones, la posibilidad de adoptar a cualquier menor de 18 años (sin restringirse a huérfanos y abandonados), al tiempo que acogía la adopción de los hijos nacidos fuera del matrimonio por su padre (Villalta, 2012: 118).

La segunda fue la ley de hijos nacidos fuera del matrimonio (Ley 14.367), aprobada el 2 de noviembre de 1954, que modificaba el estatus de los hijos denominados ilegítimos por el de extramatrimoniales. Como señalan los estudios especializados, ambas normativas, sin embargo, no alcanzaron los valores igualitaristas que se proponían inicialmente debido a que procuraron un equilibrio con el mantenimiento de la institución del matrimonio de manera que estas leyes no medraran sus alcances ni importancia como basamento social (Cosse, 2006; Giordano, Ramacciotti y

\footnotetext{
${ }^{8}$ Varias medidas influyen sobre los fenómenos demográficos, en particular las relacionadas con las políticas de vivienda, de empleo y de salud pública. Resulta evidente la relación entre políticas natalistas y antidivorcistas; entre las ventajas que a menudo conceden las legislaciones natalistas figuran los préstamos por matrimonio cuyo reembolso suele condonarse, total o parcialmente, después del nacimiento de cierto número de hijos (IUSSP y CELADE, 1982: 141). Cfr. Gonnard, 1972; Torrado et al., 1986; Masciadri, 2012a; Masciadri, 2012 b.
} 
Valobra, 2015). Es decir, se sospechaba que la igualación absoluta de los hijos matrimoniales y extramatrimoniales generaría una crisis en la institución familiar al punto que, desde el ámbito académico comentado, se llegó a sostener que tal equiparación "de índole sentimental, análoga a la que se usa a favor del divorcio" fomentaría el desorden social (Llorens y Correa Ávila, 1948: 73).

Con la tercer normativa, sancionada durante la segunda presidencia peronista en el año 1954, el poder ejecutivo nacional envió un proyecto que, durante su tratamiento en la Cámara de Diputados, dio lugar al divorcio vincular (artículo 31). Esto es, expresó una vía hasta entonces inexistente respecto de la nupcialidad que era la disolución absoluta del vínculo de manera que habilitaba contraer nuevas nupcias.

De las ampliaciones a los derechos civiles comentados arriba, la primera y la segunda ley sobrevivieron a los cambios institucionales sucedidos luego del golpe militar de 1955, mientras que la tercera sucumbió ante el decreto-ley 4.070 del 1 de marzo de 1956 que lo declaró en suspenso, paralizando los trámites judiciales iniciados y rechazando nuevas peticiones. La resistencia al cambio ${ }^{9}$ que se manifestó en la suspensión del artículo 31 tuvo su fundamento sociológico en la teoría lepleysiana que supone que "los problemas relativos al desorden social, la desmoralización de las clases populares y la difusión de la familia inestable"10 (Cicchelli-Pugeault y Cicchelli, 1999: 67) debían resolverse mediante el fortalecimiento moral de los vínculos familiares y no mediante el mejoramiento del nivel de vida.

En efecto, los autores de Demografia Argentina. Esbozo de una politica demográfica vieron los signos de desorden social en la ampliación de los derechos civiles durante el peronismo. Cierto, muchas de las medidas ideadas en la obra comentada fueron parte del Primer Plan Quinquenal (1947-1951) debido a que sus redactores —en calidad de académicosparticiparon también - en calidad de funcionarios - colaborando en el Plan de gobierno 1947-51" (Llorens y Correa Ávila, 1948; Biernat, 2007). Este elemento puntual pone en evidencia las contradicciones existentes y

\footnotetext{
${ }^{9}$ En general se piensa que todo lo que se busca explicar en relación con los seres humanos puede aclararse a partir de la consideración de individuos aislados, pero como los seres humanos se vinculan entre grupos, los conflictos son un aspecto de las estructuras sociales en convivencia: "No es la agresividad lo que desencadena los conflictos, sino los conflictos los que desencadenan la agresividad" (Elias, 2009: 186). Y el divorcio era en el tiempo revisado, un tema que según Carlos Silveyra atentaba contra "la estabilidad de la familia", la tradición, la costumbre argentina y contra toda la raza latina (1929: XXII-XXIII) - figura frecuente en el Círculo Militar, director de la revista Clarinada y miembro de la Comisión Popular Argentina contra el Comunismo (C-PACC) consideró que la tortura y el asesinato unificaban el movimiento nacionalista en su aspecto sacro. Cfr. Finchelstein, 2010: 142.

${ }^{10}$ Es decir, la "estabilidad social" se lograría apelando al espíritu de la ley paterna que funda un "orden estable" basado en la familia cristiana (Masciadri, 2012a).
} 
las fricciones ${ }^{11}$ entre los componentes conservadores e innovadores asociados pero en disputa en el gobierno de entonces. Con todo, el "problema" de la población adquirió ribetes paroxísticos hacia el año del relevamiento censal del 30 de septiembre de 1960 realizado bajo estado de sitio, cuando regía el Plan Conintes creado a fin de eliminar a las organizaciones peronistas proscritas (Pontoriero y Franco, 2013; Masciadri, 2016a, Masciadri 2016b).

Es preciso mencionar que "conforme va terminando la década del 40 , el poblacionismo de inspiración bungeana ${ }^{12}$ se acerca con más evidencia a los defensores del pensamiento tradicionalista" (Biernat, 2013: 1112) lo que condujo a que integrantes del Instituto Alejandro Bunge como Llorens y Correa Ávila utilizaran la revista Dinámica Social —integrada por nacionalistas restauradores pro-fascistas, republicanos, católicos e hispanistas - para la difusión de sus ideas según lo evidencia la edición del texto La crisis demográfica de la raza blanca de Correa Ávila (Biernat, 2013, 2007; González Bollo, 2010). Esta referencia parece vincularse con el desplazamiento de la esfera administrativa de José Figuerola, quien renunció cuando la Dirección Nacional de Información Estadística y Censos (DNIEC $)^{13}$ quedó bajo control de la Secretaría Técnica. Es decir, cuando el médico Raúl Mendé — cuadro del partido peronista y dirigente de la juventud de la Acción Católica Argentina - dejó de ser el secretario de estado para convertirse en Ministro de Asuntos Técnicos, luego de la reforma constitucional de 1949. Estos cambios se reflejan en los elencos a cargo del Segundo Plan Quinquenal (1953-1957): miembros del Instituto Étnico Nacional —organismo de investigación del gobierno (Biernat, 2007: 63) dependiente del Ministerio de Asuntos Técnicos y de la Dirección Nacional de Migraciones - que consideraban relevante favorecer "la regulación de las uniones ilegítimas" y suprimir "discriminaciones públicas y oficiales

\footnotetext{
${ }^{11}$ La ley 13.010 que consagró el voto femenino en 1947 , la ley 13.252 de 1948 y la ley 14.367 de 1954 que modificaron el status de los hijos nacidos fuera del matrimonio; la reforma de la Constitución de 1949 que equiparó jurídicamente a varones y mujeres en el matrimonio y en la patria potestad; el divorcio vincular en 1954, año en que además se eleva la edad mínima al matrimonio a 14 años para las mujeres y a 16 años para los varones (Llorens y Correa Ávila, 1948: 53; Torrado, 1993: 267-269; Barrancos, 2007).

${ }_{12}$ La demografía comprende también, el estudio de las doctrinas demográficas o teorías de la población pues intenta explicar y prever "la evolución de los fenómenos demográficos y poner de manifiesto sus consecuencias" (IUSSP y CELADE, 1982: 19; Gonnard, 1972; Vetta y Courgeau, 2003). En lo que hace al tema existen estudios contemporáneos que consideran que el divorcio disminuye la calidad de la población con el aditivo que eventualmente, dichas teorías pueden servir de base para adoptar políticas.

${ }^{13}$ La DNIEC tenía como propósito centralizar datos primarios para el lograr de los objetivos económicos y de defensa nacional; dependía del Consejo de Defensa Nacional y de la Secretaría Técnica de la Presidencia.
} 
entre los llamados hijos legítimos e ilegítimos" (Biernat, 2013: 14; Santana, 2010).

Hasta acá se han visto los pilares conceptuales sobre los que se apoyó la política demográfica para el control de la nupcialidad. Del mismo modo conviene advertir que los aspectos de la política demográfica comentados incidieron en el registro demográfico generando problemas en términos de medición. De modo que se describen las características de los matrimonios de la provincia de Buenos Aires y los partidos seleccionados para revisar luego, los datos poblacionales correspondientes a los años 1947 y 1960.

\section{LA FRECUENCIA DE LOS MATRIMONIOS}

Como se dijo, el análisis de la frecuencia de los matrimonios y de la disolución de los mismos representa, en parte, la base para los estudios de nupcialidad. Pero no hay que olvidar que el tiempo histórico se inscribe en la generación y viceversa, determinando experiencias diferenciadas según edad, cohorte y sexo que, en la medida de lo posible deben atenderse. Entre las normas y las costumbres que se empleaban para confirmar el acuerdo de unión entre un varón y una mujer se sabe que la ceremonia matrimonial era la más frecuente, de ahí que las estadísticas de matrimonios proveen datos para los estudios específicos.

Una de las dificultades en éste estudio es que la frecuencia de matrimonios registrada es fragmentaria, lo que dificulta conformar una serie temporal y geográfica extensa y homogénea para el cálculo de la tasa bruta de nupcialidad. No obstante, los datos indican que la tasa bruta de nupcialidad de la provincia de Buenos Aires fue levemente superior a la del país en el periodo 1947-1960 (Tabla 1). Entre los partidos seleccionados, General San Martín exhibió las más elevadas, La Plata se ubicó próxima a las provinciales y Chascomús mostró tasas inferiores salvo en 1949. En la serie nacional, el punto máximo (8.7 matrimonios por mil) se ubicó en 1947 momento a partir del cual la medida decrece. En la provincia de Buenos Aires, la tasa pasó de 9.1 por mil, en 1947 a 7.5 por mil, en 1960 .

$\mathrm{Al}$ disponer de la frecuencia de matrimonios por edad de los cónyuges y si se calculan tasas específicas de primonupcialidad se advierten diferencias por sexo y año de observación (Tabla 2). Como se verá luego, los incrementos en los índices de masculinidad registrados en 1947, a partir del grupo 35-39, tuvieron su repercusión en la soltería masculina. 
La nupcialidad en Buenos Aires a mediados del siglo XX: Chascomús, La Plata y San Martín / V. MASCIADRI

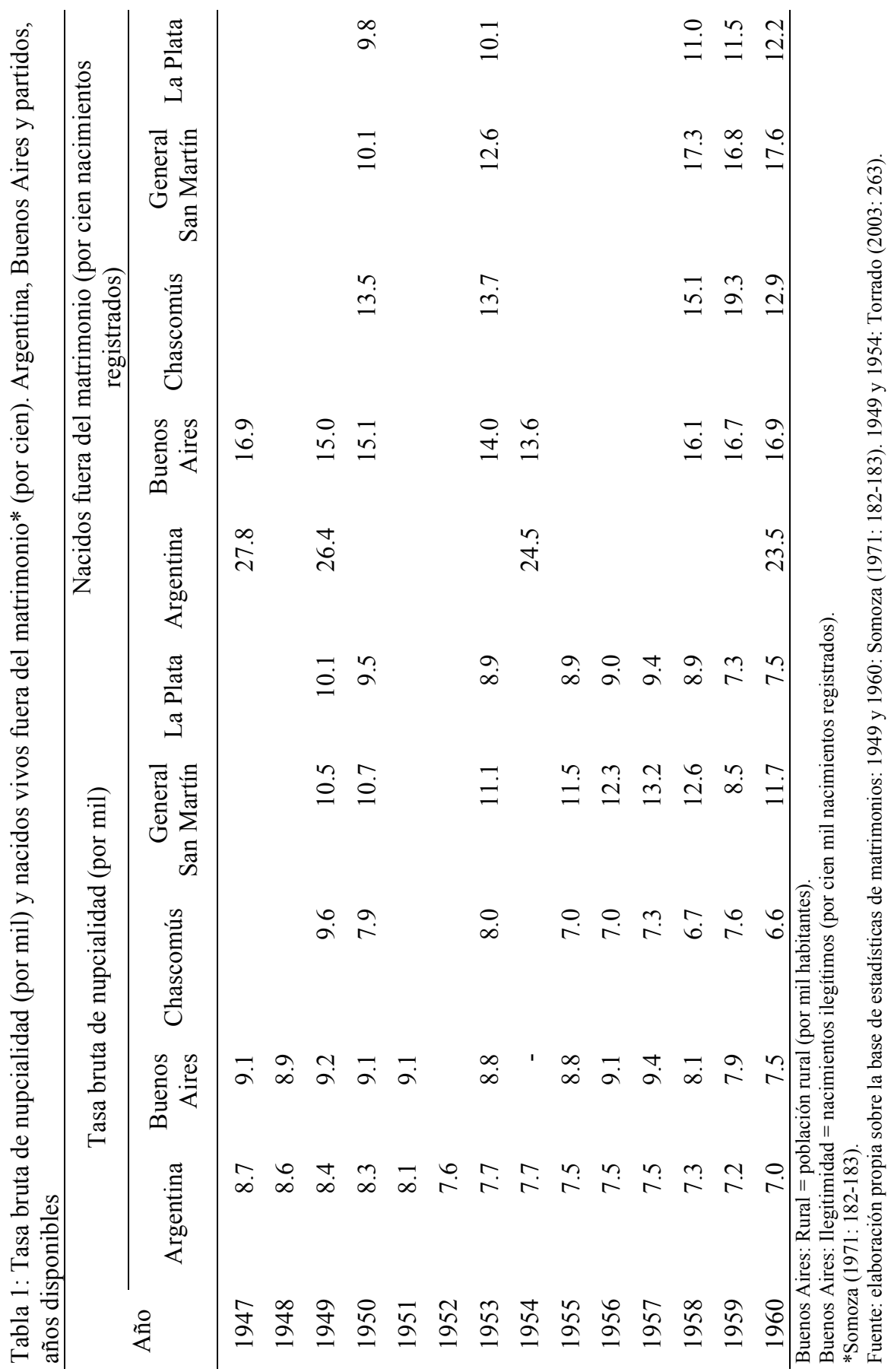


Tabla 2: Tasas específicas de primonupcialidad por grupos quinquenales de edad y sexo (por mil), índice sintético de primonupcialidad (ISPN) y edad media al primer matrimonio (EMM). Buenos Aires, 1947 y 1960

\begin{tabular}{lrrrr}
\hline & \multicolumn{4}{c}{ Sexo y año censal } \\
\cline { 2 - 5 } Grupos de edad, & \multicolumn{4}{c}{ Varones } \\
\cline { 2 - 5 } indice, edad media & 1947 & 1960 & 1947 & 1960 \\
\cline { 2 - 5 } & 2.9 & 4.8 & 1.0 & 42.0 \\
$15-19$ & 63.3 & 66.7 & 61.1 & 141.4 \\
$20-24$ & 133.1 & 135.0 & 246.8 & 140.4 \\
$25-29$ & 89.3 & 98.0 & 191.5 & 90.3 \\
$30-34$ & 57.6 & 61.4 & 119.8 & 58.7 \\
$35-39$ & 33.1 & 58.9 & 80.2 & 60.4 \\
$40-49$ & 375 & 425 & 700 & 533 \\
ISPN & 31.2 & 31.6 & 32.1 & 29.3 \\
EMM &
\end{tabular}

* matrimonios de soltero(a)s/población soltera.

Fuente: elaboración sobre la base de estadísticas de matrimonios.

Pero además, la intensidad de la nupcialidad de las mujeres en 1947 parece haber sido notable (700 por mil) con tasas en las edades 25-29, 30-34, 35-39 y 40-49 que superaron, holgadamente, la correspondiente al grupo 20-24. Esto pone en evidencia una experiencia particular en la nupcialidad de las cohortes de mujeres que, en 1947, tenían entre 25-49 años de edad. Es por eso que en 1947, la edad media de ingreso al matrimonio de los solteros (31.2 años) fue inferior a la de ingreso de las solteras (32.1 años), por tanto la nupcialidad femenina por encima de los 25 años aumentó debido a los altos índices de masculinidad descriptos en la Figura 3.

Ciertamente, en 1960, cuando los índices de masculinidad cambian, la edad media al matrimonio de solteros fue mayor (31.6 años) que la de solteras (29.3 años) al tiempo que, las tasas específicas de primonupcialidad vuelven a ser más intensas entre las mujeres de 15 a 19 años y de 20 a 24 años, aproximándose a las de los varones a partir del grupo 25-29 años (Tabla 2). Siendo que las parejas son sistemas cuasi invariantes, cuando se extinguen los efectos de cohorte reaparece la tendencia implantada en el sistema social referida a la diferencia de edad entre los cónyuges (Masciadri, 2006).

La nupcialidad comprende, asimismo, los estudios sobre endogamia, exogamia, homogamia y heterogamia; también, los estudios sobre matrimonios mixtos. El primer término se refiere a prácticas vinculadas con la 
elección de cónyuge dentro de un mismo grupo — geográfico, social, religioso y demás- definiéndose la exogamia por oposición.

Según se aprecia en la Figura 1, entre 1937 y 1960, los matrimonios según origen evidenciaron cambios. El porcentaje de matrimonios entre argentinos ascendieron de 72.9 por ciento en 1937 a 83.6 por ciento en 1960. Los casamientos entre extranjeros disminuyeron pasando de 7.7 por ciento a tres por ciento entre 1937 y 1948, año en que repuntaron para representar 6.2 por ciento en 1960. Los matrimonios mixtos de argentinos con extranjeras fueron regulares, mientras que los de extranjeros con argentinas mermaron de 15.6 por ciento en 1937 a 6.4 por ciento en 1960 .

Como era de esperar, si se revisa la distribución de los matrimonios por estado civil — solteros o viudos - 96 por ciento de los matrimonios producidos en 1950, en provincia de Buenos Aires, fueron entre solteros. En cuanto a la nacionalidad, 85 por ciento de los matrimonios provinciales corresponde a nativos: por encima de ese porcentaje se ubicó Chascomús y, por debajo, La Plata y General San Martín. Asimismo, el porcentaje provincial de matrimonios entre extranjeros alcanzó a 4.6 por ciento: sobre ese guarismo destacó General San Martín y La Plata, y en Chascomús se celebraron sólo tres matrimonios entre extranjeros (Tabla 3).

Los matrimonios mixtos son aquellos que se contraen entre personas con características diferentes como nacionalidad o religión. ${ }^{14}$ Es decir, 10.5 por ciento (4 286 casos) del total de los matrimonios fueron mixtos de los cuales 15.6 por ciento (466 casos), 10.5 por ciento (317 casos) y 7.2 por ciento (13 casos) corresponden a General San Martín, La Plata y Chascomús, respectivamente (Tabla 3 ).

Como afirma Fernando Devoto (2004: 328), los matrimonios, con quién se casa cada quien, "parece decir mucho acerca de prejuicios y estereotipos y acerca de las formas - étnicas o no- de la sociabilidad en el ámbito familiar" y en el espacio más amplio. Motivo por el cual los matrimonios mixtos propician patrones culturales y formas de interacción muy diferentes a las de los matrimonios endogámicos. Aunque para Susana Torrado (2003: 311), los matrimonios mixtos entre varón extranjero y mujer argentina "no indujeron a la naturalización" del varón pero si de la mujer quien adoptó las ideas foráneas como propias.

${ }^{14}$ No se puede conocer mediante el censo la composición según religión de los matrimonios. Sin embargo se puede comprobar el dominio del catolicismo: en 1947, 96 por ciento y en 1960, 93 por ciento de la población bonaerense se declaró católica. De los partidos seleccionados, Chascomús exhibió el mayor porcentaje (98 y 97 por ciento en 1947 y 1960, respectivamente) (Anexo 1). 


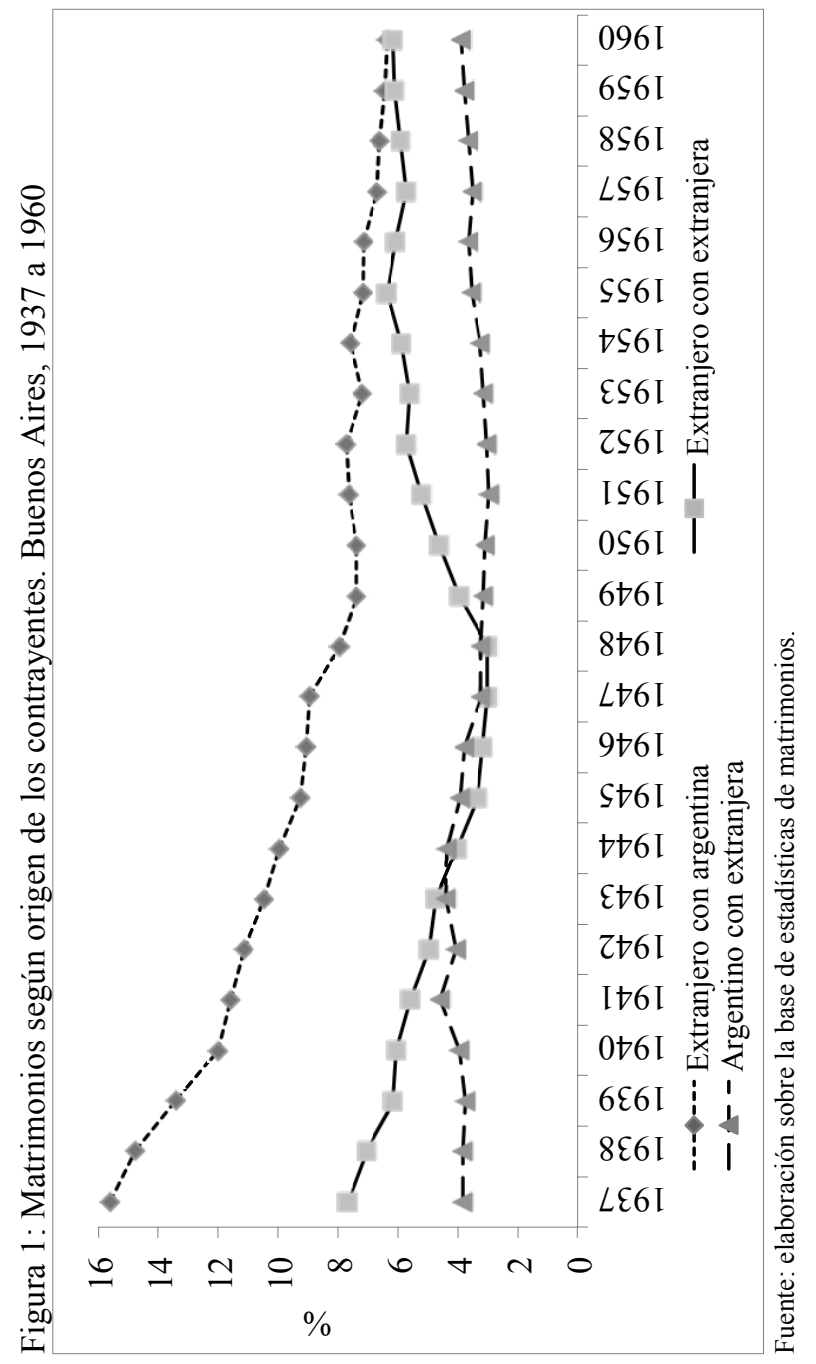


Tabla 3: Matrimonios según estado civil y nacionalidad de los contrayentes. Buenos Aires y partidos, 1950

\begin{tabular}{lrrrr}
\hline Matrimonios & $\begin{array}{r}\text { Buenos } \\
\text { Aires }\end{array}$ & Chascomús & $\begin{array}{r}\text { General } \\
\text { San Martín }\end{array}$ & La Plata \\
\hline Total matrimonios & 40812 & 181 & 2988 & 3013 \\
Solteros con solteras & 96.2 & 95.6 & 95.2 & 96.3 \\
Solteros con viudas & 1.5 & 1.1 & 1.8 & 1.6 \\
Viudos con solteras & 1.7 & 3.3 & 2.2 & 1.5 \\
Viudos con viudas & 0.6 & & 0.7 & 0.6 \\
Argentinos con argentinas & 34633 & 165 & 2263 & 2548 \\
\% total matrimonios & 84.9 & 91.2 & 75.7 & 84.6 \\
Extranjeros con extranjeras & 1893 & 3 & 259 & 148 \\
\% total matrimonios & 4.6 & 1.7 & 8.7 & 4.9 \\
Matrimonios mixtos & 4286 & 13 & 466 & 317 \\
\% total matrimonios & 10.5 & 7.2 & 15.6 & 10.5 \\
Extranjeros con argentinas & 3019 & 10 & 319 & 222 \\
\% total matrimonios mixtos & 70.4 & & 68.5 & 70.0 \\
Argentinos con extranjeras & 1267 & 3 & 147 & 95 \\
\% total matrimonios mixtos & 29.6 & & 31.5 & 30.0 \\
\hline Fuente: elaboración propia sobre la base de estadísticas de matrimonios. & &
\end{tabular}

Se conoce que el indicador más importante de asimilación o fusión es el de las pautas matrimoniales de los inmigrantes. Pese a su relevancia, sólo se obtuvieron datos sobre matrimonios por nacionalidad y sexo de los contrayentes a nivel provincial para 1950, que posibilitaron el cálculo del porcentaje de endogamia por sexo (Tabla 4).

Entre los varones extranjeros, los paraguayos fueron los más endogámicos (44.6 por ciento) seguidos por los polacos, italianos, otros europeos, españoles, portugueses, rusos, alemanes y uruguayos. Entre las mujeres extranjeras, las portuguesas fueron las más endogámicas (68 por ciento) seguidas de las italianas, polacas, otras europeas, rusas, españolas, paraguayas, alemanas y uruguayas. Es posible que la endogamia haya declinado a propósito, por ejemplo, del descenso de los flujos migratorios de países como Italia y España (Devoto, 2004: 337) lo que se vislumbró más intensamente entre los varones (Tabla 4).

Finalmente hay que destacar que no se han encontrado registros de matrimonios y divorcios que identifiquen la promoción o, en su defecto, el número de divorcios por año. Datos parciales remiten a la cifra de 1.500 casos en todo el país (Rodríguez Molas, 1984: 121) durante la vigencia del artículo 31. Sin embargo, si se observa la estacionalidad de los matrimonios se advierte una irregularidad en junio de 1956 que podría obedecer 
al incremento de matrimonios de parejas en las cuales, al menos uno se encontraba divorciado legalmente (Tabla 5).

Tabla 4: Matrimonios endogámicos según nacionalidad por sexo. Buenos Aires, 1950

\begin{tabular}{|c|c|c|c|}
\hline Posición & Endogamia & Matrimonios & $\%$ endogamia \\
\hline & Varones & & \\
\hline 1 & Argentinos/Argentinas & 35900 & 96.5 \\
\hline 2 & Paraguayos/Paraguayas & 92 & 44.6 \\
\hline 3 & Polacos/Polacas & 396 & 38.9 \\
\hline 4 & Italianos/Italianas & 2108 & 33.5 \\
\hline 5 & Otros europeos/Otras europeas & 297 & 30.0 \\
\hline 6 & Españoles/Españolas & 994 & 29.0 \\
\hline 7 & Portugueses/Portuguesas & 127 & 26.8 \\
\hline 8 & Rusos/Rusas & 78 & 25.6 \\
\hline 9 & Alemanes/Alemanas & 81 & 23.5 \\
\hline 10 & $\begin{array}{l}\text { Uruguayos/Uruguayas } \\
\text { Mujeres }\end{array}$ & 157 & 7.0 \\
\hline 1 & Argentinas/Argentinos & 37652 & 92.0 \\
\hline 2 & Portuguesas/Portugueses & 50 & 68.0 \\
\hline 3 & Italianas/Italianos & 1253 & 56.3 \\
\hline 4 & Polacas/Polacos & 278 & 55.4 \\
\hline 5 & Otras europeas/Otros europeos & 174 & 51.1 \\
\hline 6 & Rusas/Rusos & 41 & 48.8 \\
\hline 7 & Españolas/Españoles & 725 & 39.7 \\
\hline 8 & Paraguayas/Paraguayos & 108 & 38.0 \\
\hline 9 & Alemanas/Alemanes & 64 & 29.7 \\
\hline 10 & Uruguayas/Uruguayos & 109 & 10.1 \\
\hline
\end{tabular}

Nota: el total de matrimonios en 1950 fue de 40812 y de ese total se sustrajo 2.3 por ciento debido a la diversidad de nacionalidades (940 casos, 258 mujeres y 582 varones).

Fuente: elaboración propia sobre la base de estadísticas de matrimonios. 
Tabla 5: Matrimonios según mes de ocurrencia. Buenos Aires, 1947-1957*

\begin{tabular}{|c|c|c|c|c|c|c|c|c|}
\hline & 1947 & 1948 & 1949 & 1950 & 1953 & 1955 & 1956 & 1957 \\
\hline \multicolumn{9}{|c|}{ Total de matrimonios por mes de ocurrencia } \\
\hline & 38806 & 39230 & 40388 & 40812 & 42117 & 42972 & 45060 & 47444 \\
\hline Enero & 2727 & 3392 & 3540 & 3504 & 3596 & 3836 & 3759 & 4322 \\
\hline Febrero & 3524 & 3464 & 4108 & 3949 & 4228 & 4897 & 4795 & 5728 \\
\hline Marzo & 4217 & 3399 & 4046 & 4257 & 4145 & 5123 & 4898 & 5166 \\
\hline Abril & 3704 & 4321 & 4063 & 4145 & 4551 & 4377 & 2822 & 4380 \\
\hline Mayo & 3074 & 2697 & 2863 & 2866 & 2946 & 3060 & 3394 & 3858 \\
\hline Junio & 2655 & 2267 & 2711 & 2771 & 2637 & 2813 & 5069 & 2678 \\
\hline Julio & 2856 & 3026 & 2768 & 2925 & 2755 & 2623 & 2631 & 2740 \\
\hline Agosto & 2466 & 2105 & 2256 & 2488 & 2466 & 2197 & 2764 & 2902 \\
\hline Septiembre & 3117 & 2970 & 3224 & 3243 & 3017 & 3243 & 3366 & 3467 \\
\hline Octubre & 3567 & 4231 & 3800 & 3509 & 4053 & 3380 & 4008 & 4135 \\
\hline Noviembre & 3135 & 3401 & 3157 & 3354 & 3585 & 3232 & 3776 & 3927 \\
\hline Diciembre & 3764 & 3957 & 3852 & 3801 & 4138 & 4191 & 3778 & 4141 \\
\hline \multicolumn{9}{|c|}{ Porcentaje por mes de ocurrencia } \\
\hline Enero & 7.0 & 8.6 & 8.8 & 8.6 & 8.5 & 8.9 & 8.3 & 9.1 \\
\hline Febrero & 9.1 & 8.8 & 10.2 & 9.7 & 10.0 & 11.4 & 10.6 & 12.1 \\
\hline Marzo & 10.9 & 8.7 & 10.0 & 10.4 & 9.8 & 11.9 & 10.9 & 10.9 \\
\hline Abril & 9.5 & 11.0 & 10.1 & 10.2 & 10.8 & 10.2 & 6.3 & 9.2 \\
\hline Mayo & 7.9 & 6.9 & 7.1 & 7.0 & 7.0 & 7.1 & 7.5 & 8.1 \\
\hline Junio & 6.8 & 5.8 & 6.7 & 6.8 & 6.3 & 6.5 & 11.2 & 5.6 \\
\hline Julio & 7.4 & 7.7 & 6.9 & 7.2 & 6.5 & 6.1 & 5.8 & 5.8 \\
\hline Agosto & 6.4 & 5.4 & 5.6 & 6.1 & 5.9 & 5.1 & 6.1 & 6.1 \\
\hline Septiembre & 8.0 & 7.6 & 8.0 & 7.9 & 7.2 & 7.5 & 7.5 & 7.3 \\
\hline Octubre & 9.2 & 10.8 & 9.4 & 8.6 & 9.6 & 7.9 & 8.9 & 8.7 \\
\hline Noviembre & 8.1 & 8.7 & 7.8 & 8.2 & 8.5 & 7.5 & 8.4 & 8.3 \\
\hline Diciembre & 9.7 & 10.1 & 9.5 & 9.3 & 9.8 & 9.8 & 8.4 & 8.7 \\
\hline
\end{tabular}

Mediante el análisis realizado en esta sección se obtuvo un primer acercamiento a la frecuencia de los matrimonios pero todavía no se sabe demasiado sobre los divorcios. Además, se conoce que en Argentina pese a que prevaleció la monogamia y la tradición católica, el matrimonio no fue hacia 1950, la única vía para la formación de las parejas. Mediante el análisis de datos censales se procura examinar los aspectos faltantes. 


\section{LA ESTRUCTURA POR SEXO Y EDAD DE LA POBLACIÓN BONAERENSE}

La existencia del elemental mecanismo por el cual nacen y mueren individuos y del lapso que transcurre entre el nacimiento y la muerte de un mismo individuo y de todos los demás, es lo que asegura la coexistencia en el tiempo "de un número variable de personas que constituyen precisamente la población" (Pressat, 1983: 14). Las poblaciones humanas se encuentran formadas por elementos diferenciados de modo que es importante conocerlas en su estado (distribución por edad, sexo, estado civil, religión y demás) muchos de los cuales son el resultado de las huellas dejadas por los fenómenos demográficos (mortalidad, fecundidad, nupcialidad, migración) sobre la población. Uno de los fenómenos que dejó huellas visibles en las distribuciones por edad y sexo de la población argentina fue la migración.

Según información proveniente de los censos, el volumen provincial de población en 1947 era de 4272336 habitantes el que ascendió a 6766108 habitantes en 1960, representando 27 y 34 por ciento de la población argentina en los años considerados (Tabla 6). Al observar la distribución por grandes grupos de edad se advierten incrementos en el grupo 0-14 años y 65 y más, además de insinuarse diferencias entre las estructuras provincial y nacional, principalmente, en la población infantil que fue inferior en la provincia de Buenos Aires.

En cuanto a la distribución por sexo, se aprecia que los índices de masculinidad descendieron de 111 a 103; también, se observan distancias significativas entre la población rural y la proporción de niños nacidos fuera del matrimonio que, en ambos casos, se encuentran por debajo de la medida nacional (Tabla 6).

Según se dijo, para identificar las huellas que ciertos fenómenos demográficos dejaron en la población, es importante revisar la distribución por grupos de edades sino simples, al menos, por grupos quinquenales o decenales.

Hay que mencionar que la población de la provincia de Buenos Aires se caracterizó, tanto en 1947 como en 1960, por ser una población joven sin signos evidentes de envejecimiento poblacional aunque con una ligera tendencia al engrosamiento de la cúspide en 1960 y con muestras de cambios en el índice de masculinidad observados en perspectiva histórica (Figura 2a y Figura 2b). Al examinar la distribución por edad y sexo de la población de Buenos Aires se observan disimetrías. En 1947, los grupos 20-24 y 15-19 eran los más numerosos mientras que, en 1960, lo eran los grupos 0-4 y 5-9. 


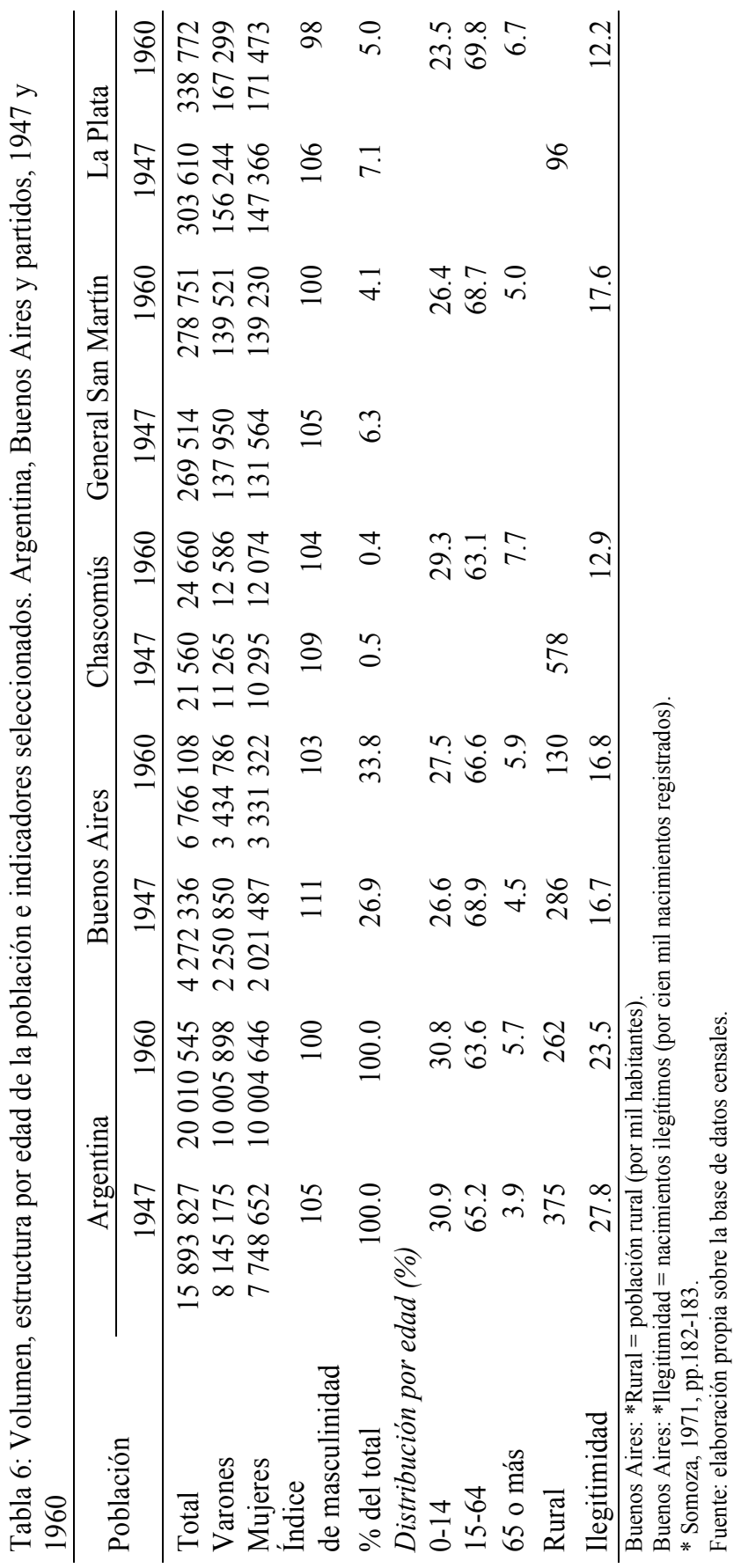


Figura 2a: Población por grupos de edad según sexo e índice de masculinidad por grupos de edad/generación. Buenos Aires, 1947

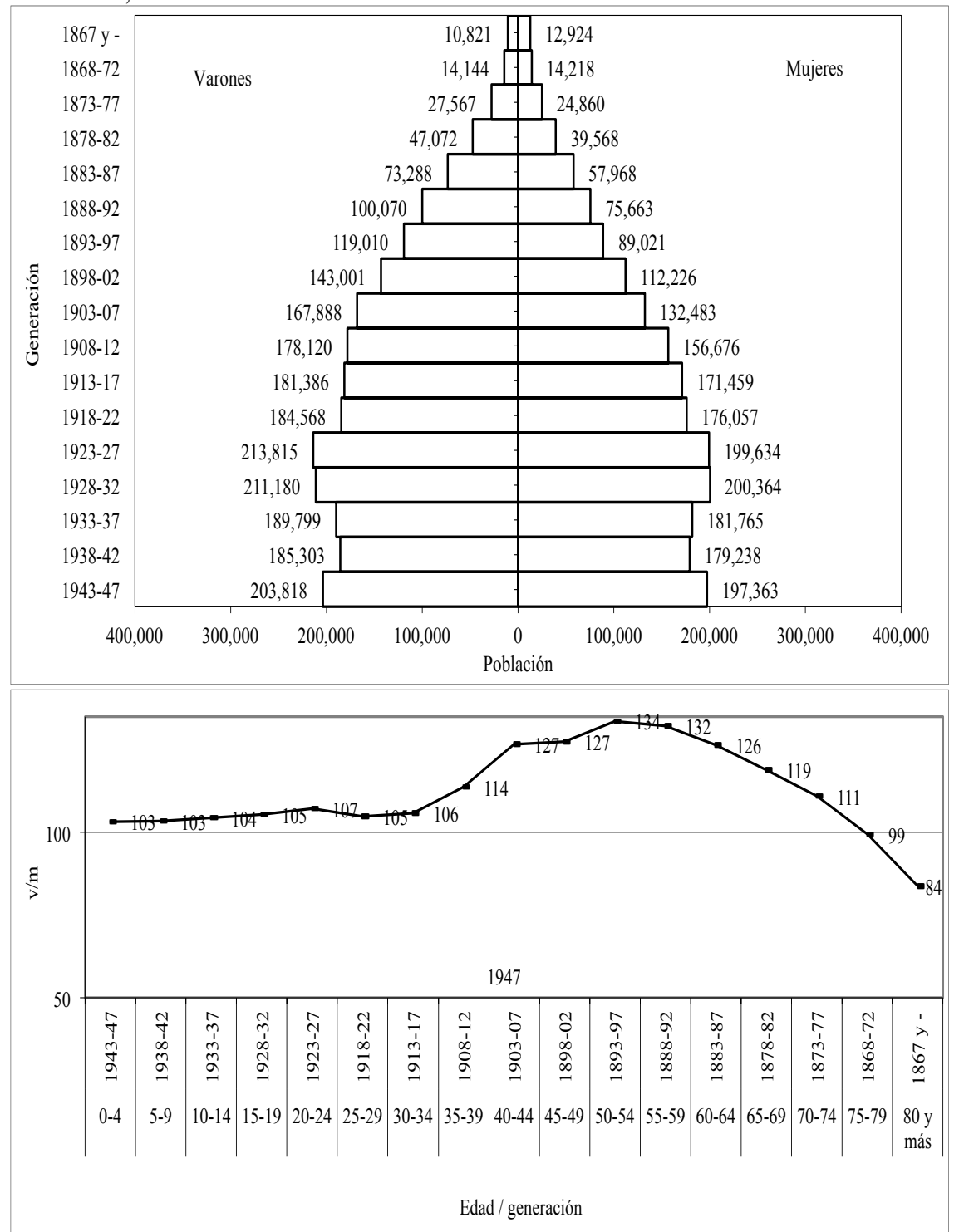

Fuente: elaboración propia sobre la base de datos censales. 
Figura 2b: Población por grupos de edad según sexo e índice de masculinidad por grupos de edad/generación. Buenos Aires, 1960
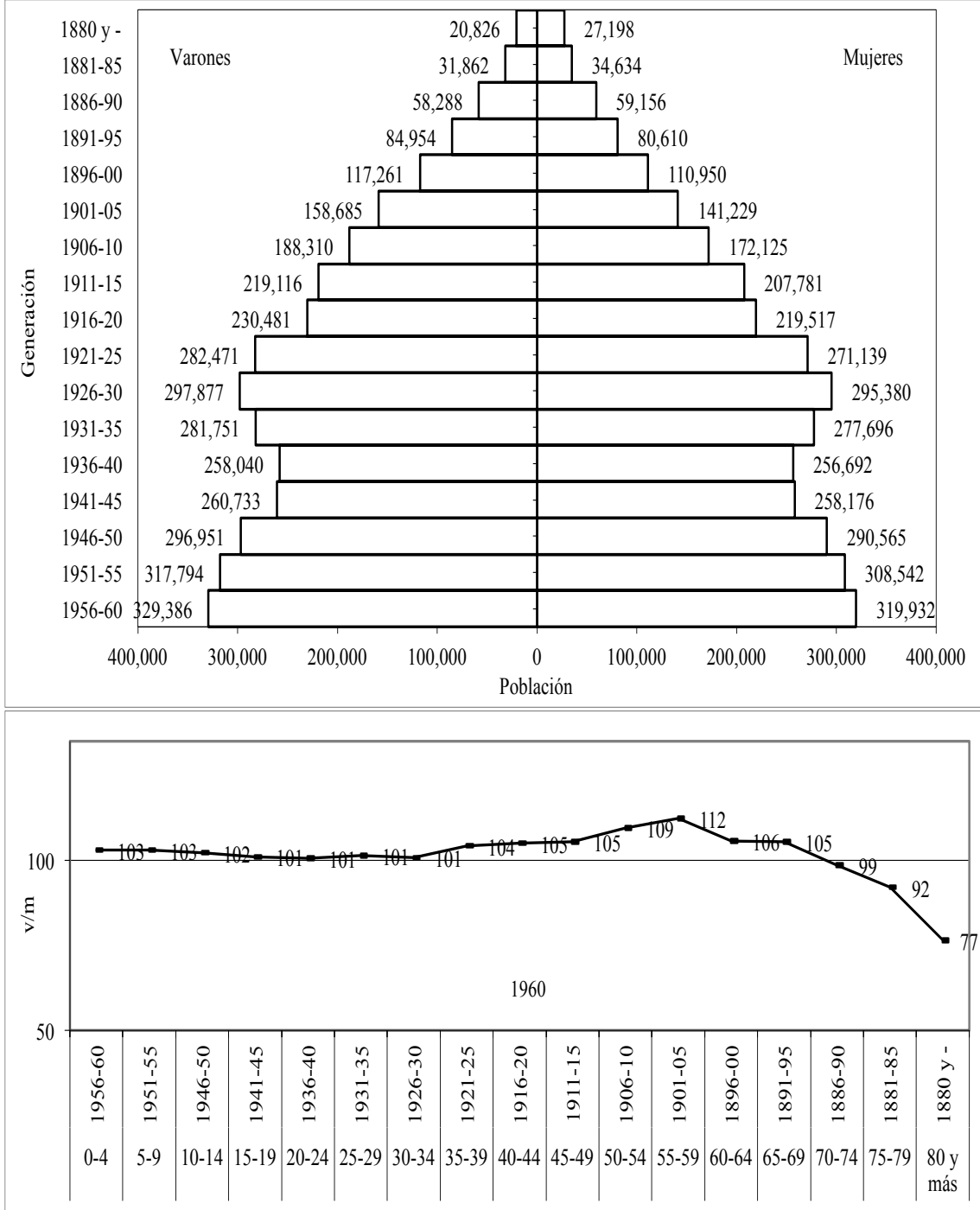

Edad / generación

Fuente: elaboración propia sobre la base de datos censales. 
Por otra parte, el incremento en los índices de masculinidad registrados en 1947, a partir del grupo 40-44 (generación 1903-1907) muestra la interferencia de las migraciones históricas lideradas por varones extranjeros la que tiende a extinguirse hacia 1960. Como se sabe, estos índices han incidido en la soltería masculina a escala nacional y regional (Masciadri, 2013) lo cual tiene su expresión a escala provincial. ${ }^{15}$

En relación con los tres partidos seleccionados, La Plata representó el de mayor volumen tanto en 1947 como en 1960, seguido de cerca por General San Martín y, muy alejado de Chascomús (Tabla 6). En otras palabras, en 1947, La Plata representó siete por ciento del total provincial mientras que General San Martín concentró seis por ciento y Chascomús 0.5 por ciento.

Si se examina la distribución por sexo, el índice de masculinidad de La Plata pasó de 106 en 1947 a 98 en 1960, el de General San Martín de 105 en 1947 a 100 en 1960, y el de Chascomús de 109 en 1947 a 104 en 1960. Al considerar la distribución urbano-rural, en el año 1947, Chascomús tenía mayor población rural (578 habitantes rurales por mil habitantes), que La Plata donde el guarismo alcanzó a los 96 habitantes rurales por mil, mientras que la conformación de General San Martín era plenamente urbana (Tabla 6).

Este hecho puntual tiene su expresión en la distribución por sexo y edad pues la población rural, mayormente masculina, exhibía índices de masculinidad muy elevados en las edades productivas jóvenes (grupos 20-29 y 10-19) aunque con diferencias en la forma de la distribución (Tabla 7): en Chascomús, los índice de masculinidad deben ser puestos en relación con la migración transoceánica, principalmente; mientras que el punto de inflexión en 1947 en el índice de La Plata, que se ubicó en el grupos 20-29 años, se explica por la recepción de población en edad productiva joven.

En síntesis, por cuanto a los efectivos casaderos presentes en ellas, las marcas históricas en la estructura por edad y sexo de la población a escala provincial tendrán repercusión, tanto en las pautas de formación y disolución de las parejas, como en la soltería. Se recuerda que 80 por ciento del aporte migratorio a la Argentina provino de países católicos -España e Italia - donde la única institución reconocida en el momento de las grandes migraciones era el matrimonio religioso (Moreno, 2007: 517) — la

${ }^{15}$ Como señala Ceva (2012: 316-317) hasta 1924, 84 por ciento de los inmigrantes tenía entre 13-60 años incluso la proporción de adultos fue mayor entre 1921-1924 cuando ascendió a 88 por ciento. En cambio, entre los arribos producidos en los años comprendidos entre 1947 y 1950 , cerca de la mitad de los inmigrantes tenía entre 22 y 40 años de edad. A partir de 1950 los valores oscilaron entre 30 y 40 por ciento disminución que se debe al ingreso de niños pues creció la tasa de ingreso de familias completas. 
ceremonia civil se instituyó pasada la Segunda Guerra Mundial- lo que motivó la sanción, en todos los estratos sociales, a ambos lados del Atlántico, "de la bastardía y de la ilegitimidad".

Tabla 7: Índice de masculinidad de la población rural por grupos decenales de edad. Chascomús y La Plata*, 1947

\begin{tabular}{lrrr}
\hline Edad & Generación & Chascomús & La Plata \\
\hline $0-9$ & $1938-1947$ & 101 & 95 \\
$10-19$ & $1928-1937$ & 119 & 159 \\
$20-29$ & $1918-1927$ & 116 & 232 \\
$30-39$ & $1908-1917$ & 142 & 151 \\
$40-49$ & $1898-1907$ & 153 & 162 \\
$50-59$ & $1888-1897$ & 171 & 171 \\
$60-69$ & $1878-1887$ & 181 & 171 \\
$70+$ & 1877 y menos & 126 & 155 \\
Total & 127 & 160 \\
\hline *no se incluye General San Martín pues su composición es urbana. \\
Fuente: elaboración propia sobre la base de datos censales.
\end{tabular}

Por el mismo motivo, a escala departamental, las huellas dejadas por la migración y captadas a través del índice de masculinidad de la población rural permiten conjeturar que a escala local, la soltería habría sido intensa entre los varones que vivieron hacia mediados de siglo XX en las zonas rurales dependiendo del partido.

\section{El ESTADO CONYUGAL DE LA POBLACiÓN: SOLTEROS, CASADOS, DIVOR- CIADOS Y VIUDOS (1947) Y SOLTEROS, CASADOS, UNIDOS DE HECHO, SEPARADOS, DIVORCIADOS Y VIUDOS (1960)}

Hacia 1947 en la Argentina del total de la población de 14 años y más, 46.5 por ciento (5 261017 personas) se declaró casada mientras que en la provincia de Buenos Aires lo hizo 51 por ciento (1 629693 personas). En General San Martín 57 por ciento (116 697 personas) se declaró casado y en La Plata lo hizo 52 por ciento (122 340 personas). Chascomús se ubicó por debajo del porcentaje nacional y provincial ya que 45 por ciento (7 085 personas) de la población se declaró casada.

La población soltera del país alcanzó a 5331143 personas (47 por ciento) y la de Buenos Aires a 1383363 personas (43 por ciento). Si se atiende a la distribución por partido, en Chascomús representó 48 por cien- 
to (7 595 personas), en La Plata 41 por ciento (98 162 personas) y en General San Martín 37 por ciento (75 298 personas).

En el país y en Buenos Aires, la población viuda rondó seis por ciento (674 235 personas y 191432 personas, respectivamente). Dicha medida relativa se replicó de modo casi idéntico en La Plata (15 519 personas), en General San Martín (11 844 personas) y en Chascomús (993 personas).

En cuanto a la población divorciada nacional alcanzó a 52501 personas (0.5 por ciento) y la provincial significó un total de 11879 personas $(0.4$ por ciento). En General San Martín la población divorciada fue de 0.6 por ciento (1 199 personas), en La Plata fue de 0.4 por ciento (1 009 personas) y en Chascomús sólo de 0.2 por ciento ( 24 personas).

Es decir, en 1960 la población soltera del país fue de 4688165 personas (34 por ciento), con una reducción de 13 puntos porcentuales en relación con el registro de 1947. En la provincia, la reducción de la población soltera fue de ocho puntos porcentuales alcanzando a 1832927 personas (35 por ciento). Entre los partidos seleccionados la mayor reducción porcentual se dio en Chascomús (7.6 puntos) seguida de La Plata (5.8 puntos) y de General San Martín (4.3 puntos).

La población viuda representó 5.7 por ciento (793 789) a escala nacional y 5.1 por ciento (269 964) a escala provincial. Por otra parte, el porcentaje de población viuda en los partidos varió levemente en relación a la medida estándar: en La Plata fue de 6.3 por ciento, en General San Martín fue de 4.9 por ciento y en Chascomús fue de 5.7 por ciento.

Por último, la población que se desvinculó voluntariamente continuó siendo mínima en Argentina: la población separada representó el 0.6 por ciento (78 626) y la divorciada el 0.1 por ciento (12 376). En Buenos Aires la población separada representó el 0.5 por ciento $(25261)$ y la divorciada el 0.1 por ciento (3 189). Similares porcentajes se replican en los partidos aunque el volumen de la población que se desvinculó voluntariamente cambia: en La Plata se declararon separadas 1517 personas (0.6 por ciento) y 317 divorciadas ( 0.1 por ciento). En General San Martín se declararon separadas 1091 personas $(0.5$ por ciento) y 153 divorciadas (0.1 por ciento). En Chascomús el guarismo fue de 73 personas separadas (0.4 por ciento) y cuatro divorciadas (Tabla $8 \mathrm{a}$, Tabla 8 b, Tabla $8 \mathrm{c}$ y Tabla $8 \mathrm{~d}$ y Anexo 2).

Si se atiende a la distribución de la población según estado civil y edad se observa que la población femenina y masculina casada de la provincia de Buenos Aires se concentró, en ambos años censales, en el grupo modal 40-49. 


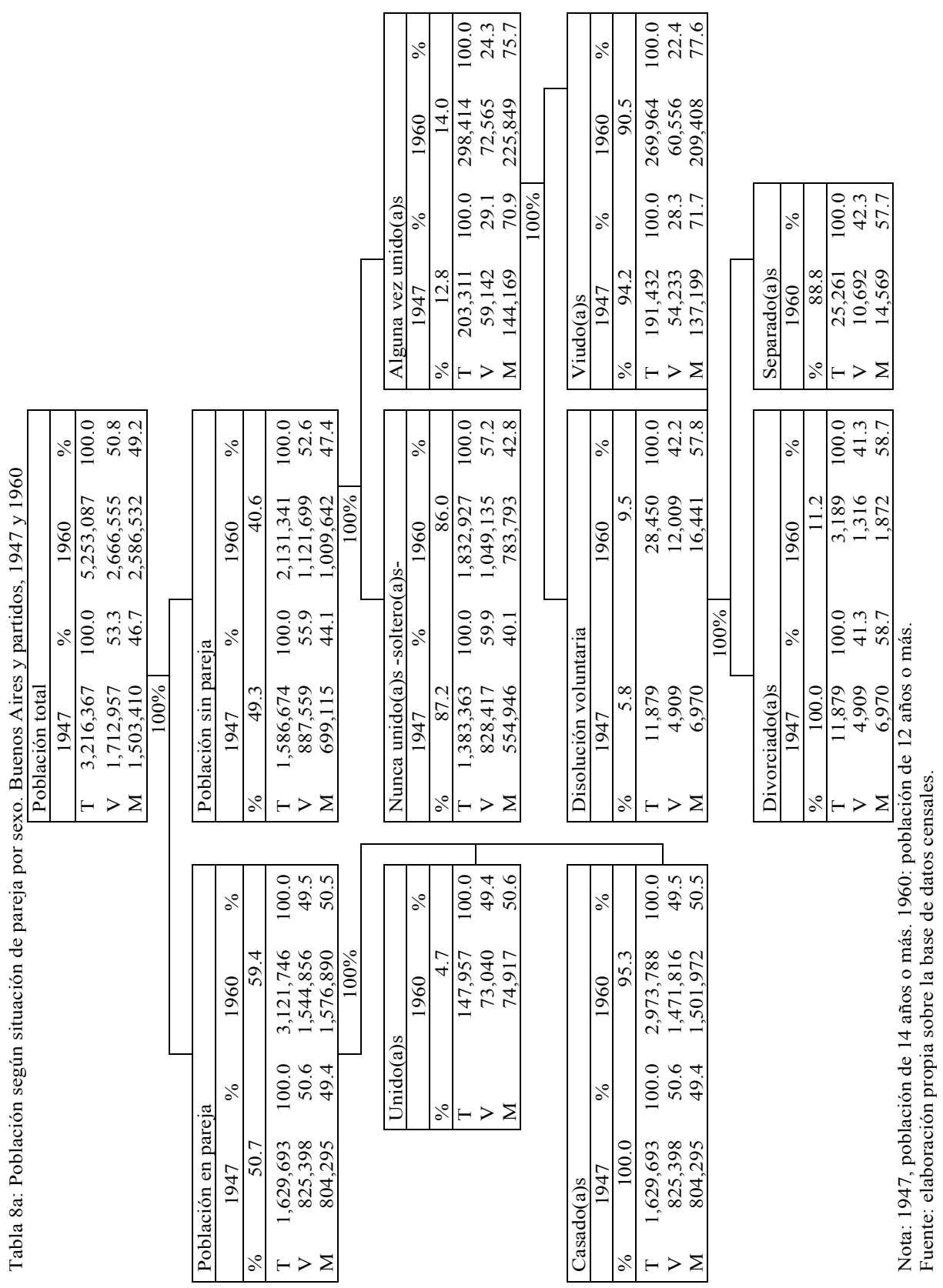




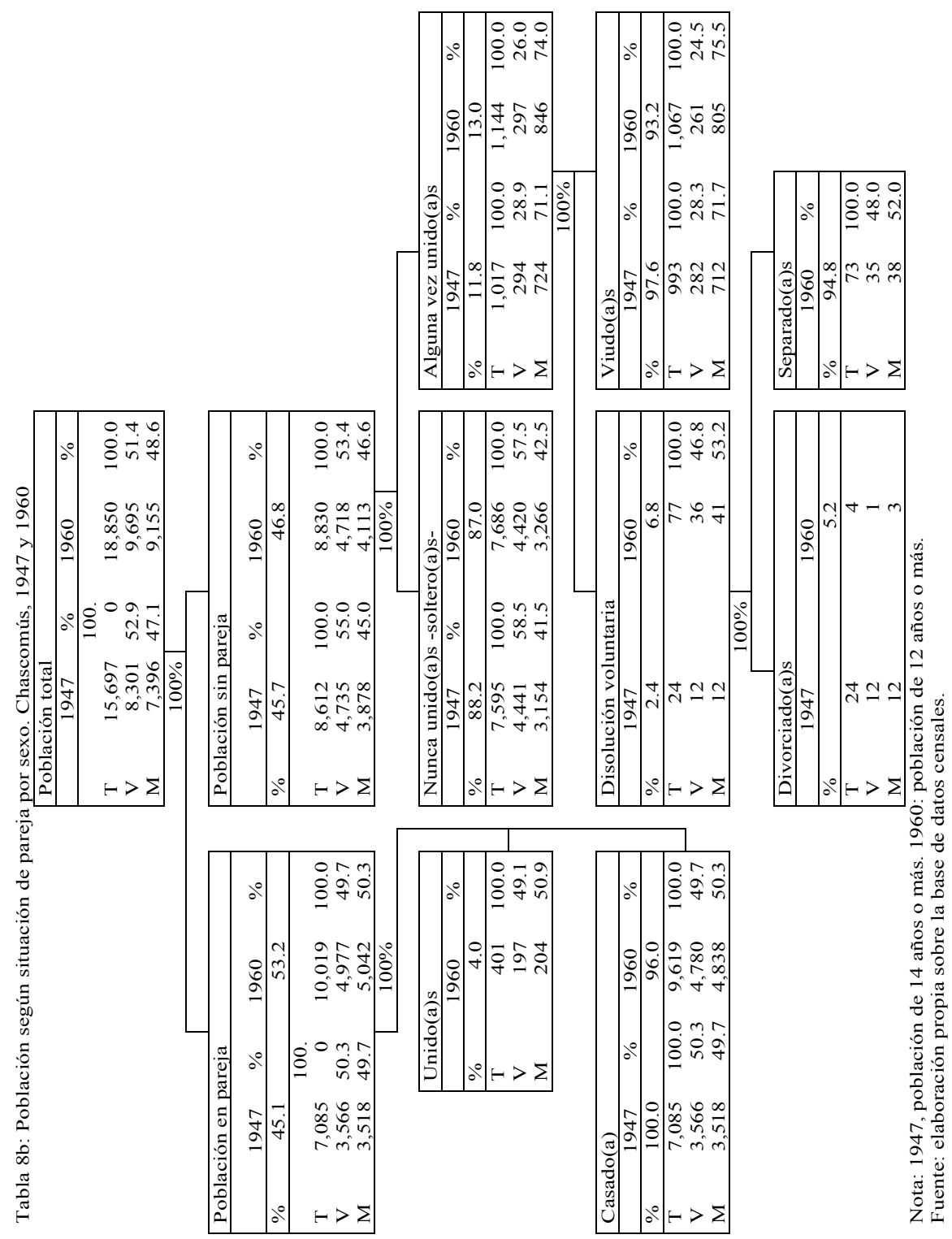




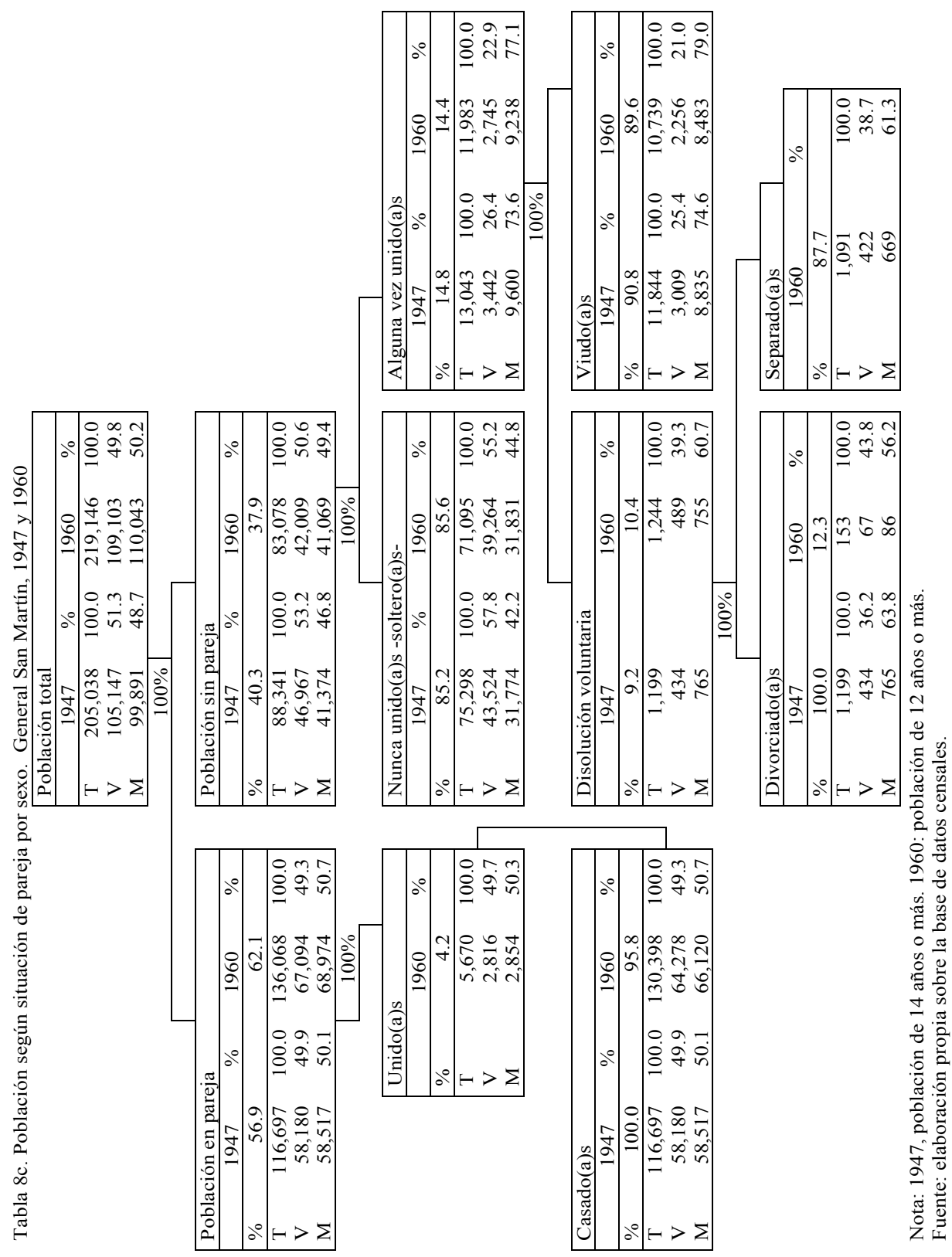




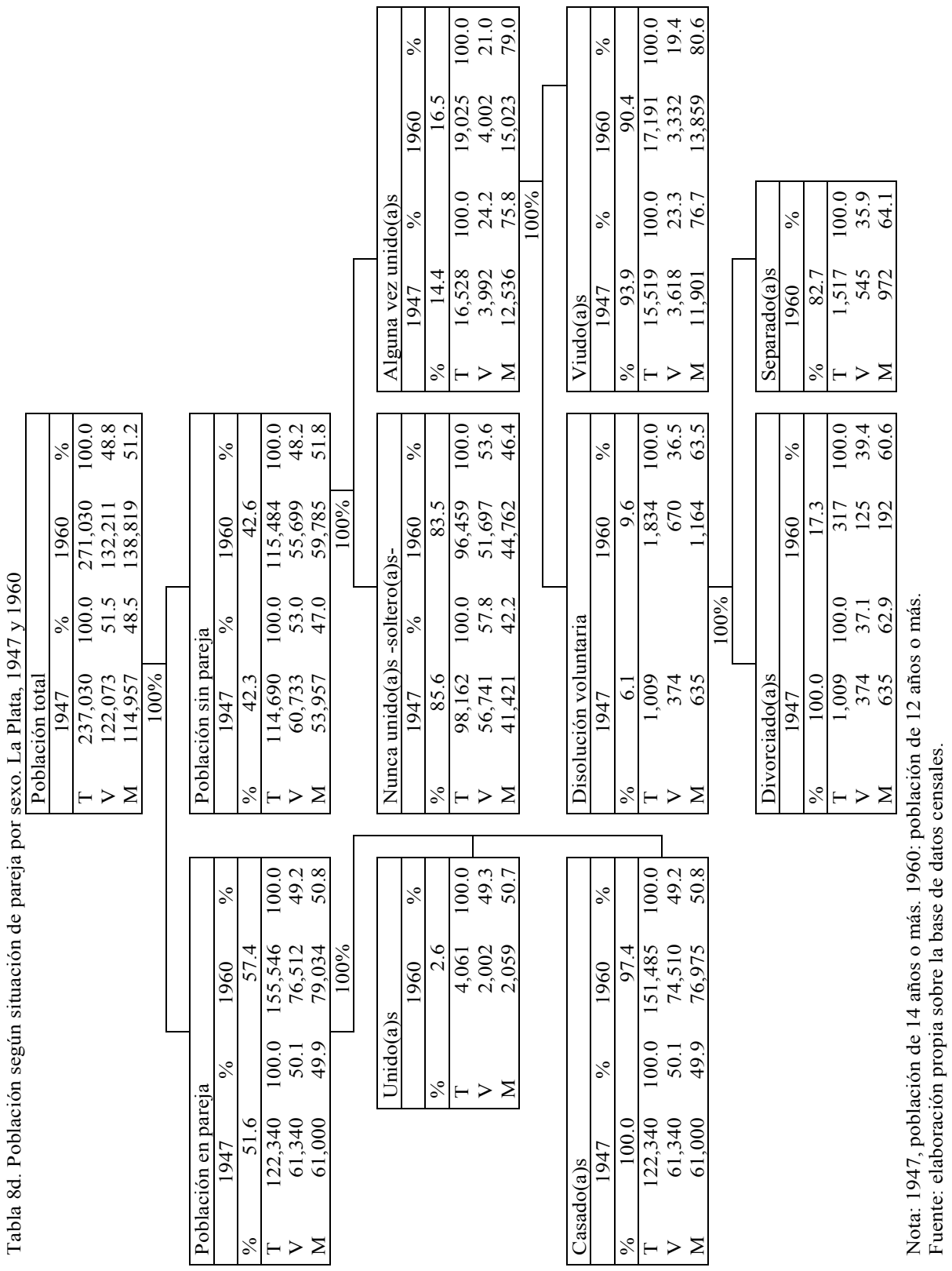


La distribución por edad varía entre mujeres y varones principalmente por los efectos de la sobremortalidad masculina que determinan una intensidad mayor de la viudez entre las mujeres.

En 1960, la población unida de hecho se concentró en el grupo modal 40-49 en ambos sexos al igual que la población divorciada con algunos corrimientos (Figura 3a y Figura 3b).

\section{LA POBLACIÓN EN PAREJA: CASADA Y COHABITANTE}

Es posible conformar la subpoblación con pareja y sin pareja si se repara en que la variable estado civil puede reagruparse. La subpoblación con pareja incluye a personas casadas y unidas consensualmente.

Es decir, en 1960, el porcentaje de uniones consensuales o solteros en unión de hecho - según la denominación del censo - fue de 7.3 por ciento a escala nacional (606 774 personas) y de 4.7 por ciento a escala provincial (147 957 personas). Asimismo, en los partidos bonaerenses seleccionados este porcentaje también fue bajo y próximo a la media provincial..

Si se calcula el porcentaje de uniones consensuales sobre el total de uniones de cada grupo de edad se obtiene que en Buenos Aires, éstas eran más frecuentes entre los más jóvenes (Tabla 9). A su vez, destaca el mayor porcentaje de varones en los cuatro primeros grupos de edad que podría estar asociado a que, algunas mujeres prefieren declararse casadas en lugar de solteras en unión consensual. ${ }^{16}$

En síntesis, Buenos Aires y los partidos seleccionados se han mostrado apegados al modelo occidental de matrimonio lo que se traduce en la escasa frecuencia de uniones consensuales y de matrimonios mixtos. Hacia 1960, la cifra de 2973988 personas casadas y de 147957 personas unidas de hecho revela los elementos aglutinantes y disruptivos en el mundo de las parejas.

\footnotetext{
${ }^{16}$ Se sabe que la legitimidad de la unión es una convención contractual normada a través de procedimientos legales, al punto que se ha constatado que "mujeres inicialmente unidas de modo consensual tienden a modificar su estado por razones de prestigio o de legitimación de sus descendientes" (Alcántara, 1983: 100).
} 
Figura 3a: Población masculina y femenina por grupos de edad según estado civil/conyugal. Buenos Aires, 1947

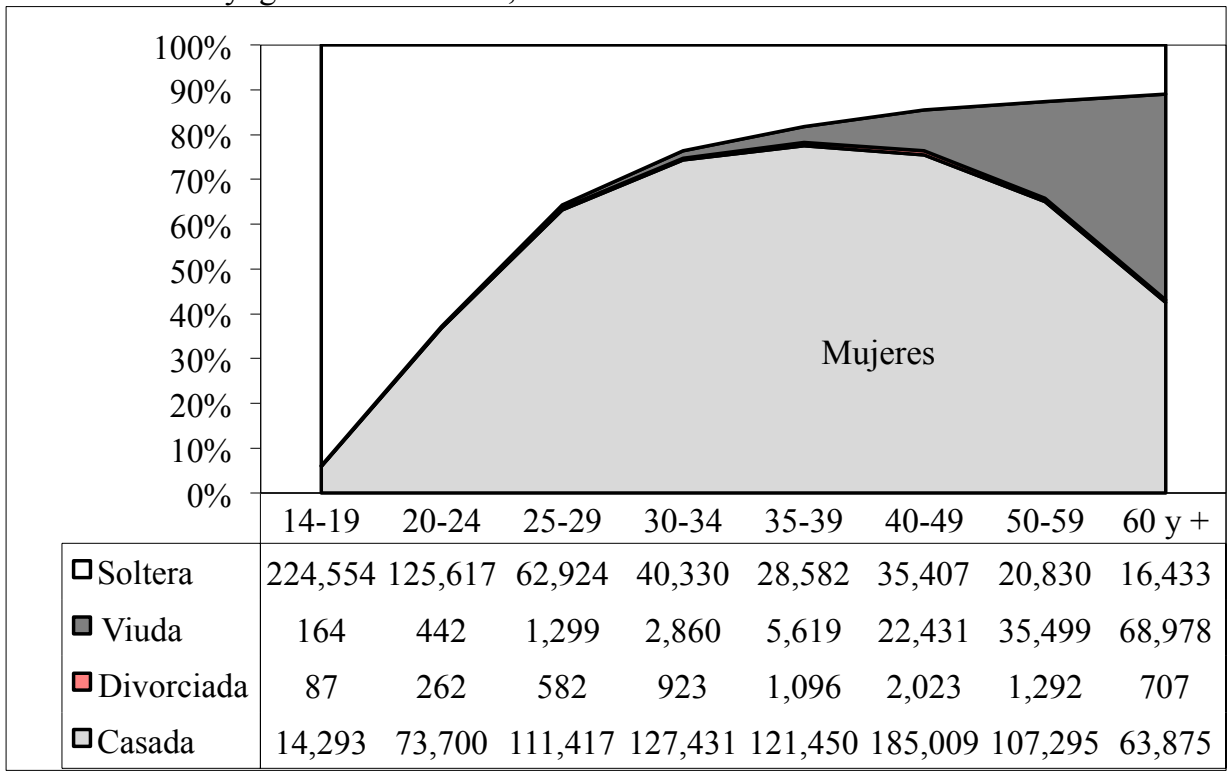

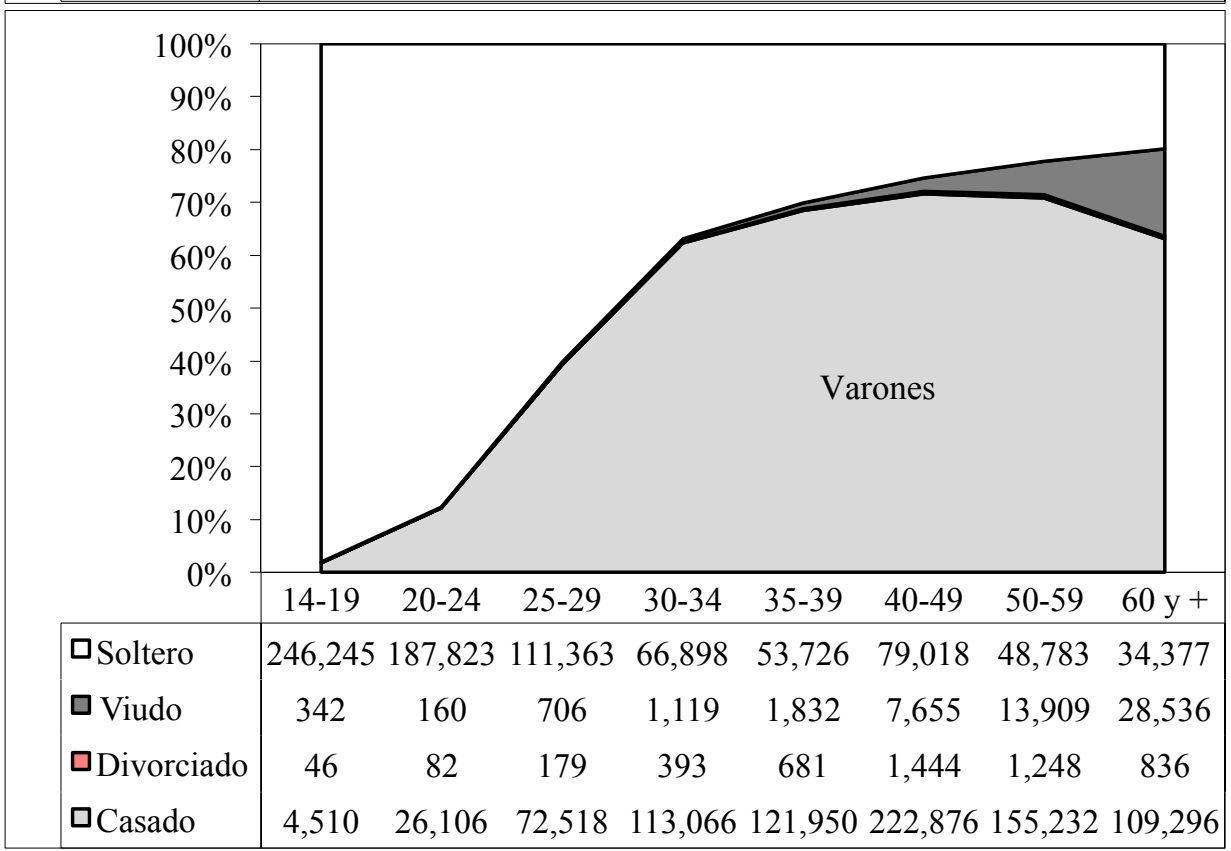

Fuente: elaboración propia sobre la base de datos censales. 
Figura 3b: Población masculina y femenina por grupos de edad según estado civil/conyugal. Buenos Aires, 1960

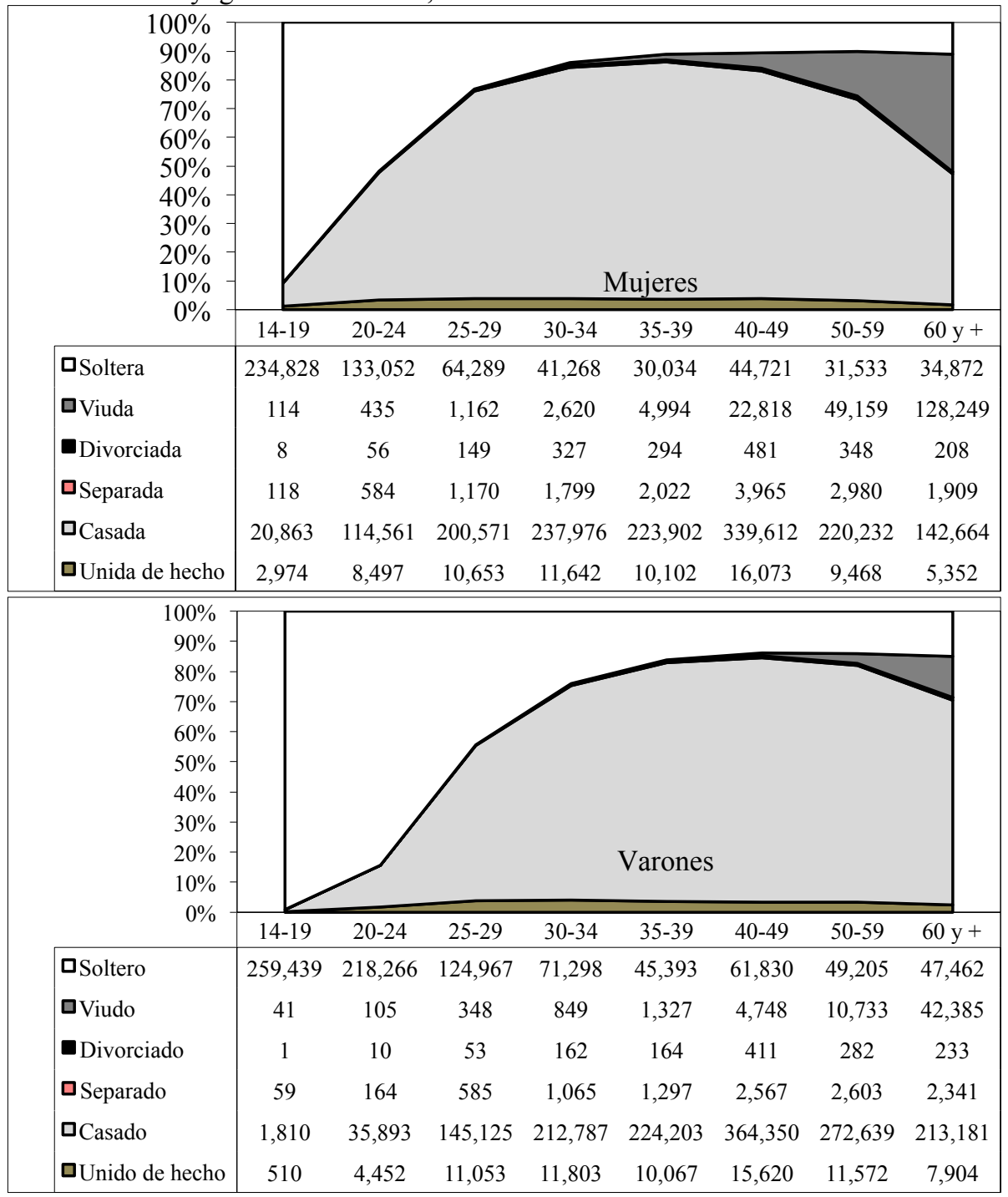

Fuente: elaboración propia sobre la base de datos censales. 
Tabla 9: Porcentaje de soltero(a)s en unión de hecho sobre el total de uniones de cada grupo de edad. Buenos Aires, 1960

\begin{tabular}{lrrrrrrrrr}
\hline & & \multicolumn{7}{c}{ Grupos de edad } \\
\cline { 3 - 10 } Sexo & Total & $15-19$ & $20-24$ & $25-29$ & $30-34$ & $35-39$ & $40-49$ & $50-59$ & $600+$ \\
\hline Varones & 4.7 & 22.0 & 11.0 & 7.1 & 5.3 & 4.3 & 4.1 & 4.1 & 3.6 \\
Mujeres & 4.7 & 12.5 & 6.9 & 5.0 & 4.7 & 4.3 & 4.5 & 4.1 & 3.6 \\
\hline
\end{tabular}

Fuente: elaboración propia sobre la base de datos censales.

\section{LA POBLACIÓN SIN PAREJA: SOLTERA, VIUDA, SEPARADA Y DIVORCIADA}

Según se vio el matrimonio era el "estado natural" hacia el cual el conjunto de la población argentina debía propender, sobre todo, las mujeres. Es por eso que, en los censos, siempre se enumeró la población soltera, casada $\mathrm{y}$ viuda. Esto es así pues se fundamentaba que a cierta edad ${ }^{17}$ había que casarse "para toda la vida" naturalizando, de este modo, el motivo por el cual un matrimonio concluía (Jelin, 1989). Ya han sido comentados los problemas que generó la ideología censal en la producción del dato (Pantelides, 1984; Cacopardo, 1996; Torrado, 2003). Con todo, en esta sección se describe a la población $\sin$ pareja ${ }^{18}$ poniendo énfasis en el colectivo que se desvinculó voluntariamente.

El índice de masculinidad de solteros por grupos de edad indica cambios en el periodo: i) en la soltería definitiva masculina, que es la que se registra a partir de los 50 años y, ii) en los índices correspondientes a edades productivas jóvenes (20-24, 25-29, 30-34) ligados a la inmigración.

En efecto, en 1947 el índice de masculinidad de solteros a la edad 5059 fue de 234 varones solteros por cada 100 mujeres solteras mientras que, en 1960 el mismo índice a la misma edad fue de 156. Lo propio sucede con el grupo abierto final. Es decir, los datos de la Tabla 10 confirman las observaciones vinculadas con la estructura por edad y sexo que anticiparon mayor soltería en varones dependiendo de la edad, la generación y la zona rural. Y reafirman lo expresado en relación con la primonupcialidad femenina (Tabla 2) por encima de los 25 años.

${ }^{17}$ Como se dijo la edad mínima fue de 14 años para las mujeres y de 16 años para los varones a partir de 1954. Actualmente se considera al matrimonio temprano como una violación de los derechos humanos y se habla de matrimonio infantil o precoz en los casos en que uno o ambos contrayentes es niño, niña o adolescente, es decir, un matrimonio formal o unión informal que sucede antes de los 18 años. Hoy la edad mínima recomendada es de 18 años pues se conoce que el matrimonio precoz se asocia a prácticas discriminatorias (Céspedes y Robles, 2016: 27).

${ }^{18}$ En Buenos Aires, la población sin pareja disminuyó entre 1947 y 1960 de 49 a 41 por ciento. Y del total de la población bonaerense sin pareja, 56 por ciento, en 1947, y 53 por ciento en 1960, eran varones lo que indica un incremento de la porción femenina en el subconjunto. 
Tabla 10: Índice de masculinidad de solteros por grupos de edad. Buenos Aires, $1947^{*}$ y 1960

\begin{tabular}{|c|c|c|c|c|c|c|c|c|c|}
\hline \multirow[b]{2}{*}{ Año } & \multirow[b]{2}{*}{ Total } & \multicolumn{8}{|c|}{ Grupos de edad } \\
\hline & & $15-19$ & $20-24$ & $25-29$ & $30-34$ & $35-39$ & $40-49$ & $50-59$ & $600+$ \\
\hline $1947(t)$ & 149 & 110 & 150 & 177 & 166 & 188 & 223 & 234 & 209 \\
\hline $1947(\mathrm{r})$ & 229 & 139 & 227 & 258 & 294 & 341 & 438 & 549 & 492 \\
\hline $1960(\mathrm{t})$ & 143 & 110 & 164 & 194 & 173 & 151 & 138 & 156 & 136 \\
\hline
\end{tabular}

Otro aspecto de los estudios sobre nupcialidad concierne al concepto de vida conyugal, la que concluye por fallecimiento de uno de los cónyuges o por divorcio (IUSSP y CELADE, 1982). Así y todo, en la provincia de Buenos Aires la población alguna vez unida representó, en 1947, 13 por ciento y, en 1960, 14 por ciento de la población de 14 años o más, repartición que se replicó con leves distancias en los partidos. El escaso incremento en la población alguna vez unida se explica por la incipiente pero mayor incidencia de la disolución voluntaria del matrimonio (o la unión) frente, a la menor incidencia de la disolución involuntaria del matrimonio (o la unión) por fallecimiento de uno de los cónyuges.

Por cierto, Somoza (1971: 26) estimó la esperanza de vida al nacer del periodo 1946-1948 en 59.09 años en varones y en 63.59 años en mujeres ascendiendo, en el periodo 1959-1961, a 63.68 años y a 69.53 años respectivamente. Es decir, la disminución en el nivel de la mortalidad incrementó el tiempo de vida matrimonial, la disolución voluntaria de los matrimonios y la viudez entre las mujeres.

En cuanto a la disolución voluntaria de la unión, los datos del Tabla 11 muestran que más del 50 por ciento de las personas divorciadas (1947) y separadas/divorciadas (1960) en cada grupo de edad eran mujeres, con la excepción del grupo abierto final. Hay que comprender que ambos, varones y mujeres, se separan o se divorcian en igual medida pero condicionamientos múltiples hacen que, las mujeres evidencian una propensión menor a formar nuevas uniones.

Mediante el cálculo de la probabilidad de estar divorciado se deduce que su ocurrencia fue escasa: siete por mil a nivel provincial en $1947 \mathrm{y}$ ocho por mil en 1960 para ambos sexos. Si bien en 1947, la probabilidad fue muy baja en todos los partidos, General San Martín y La Plata superaron levemente la medida provincial mientras que Chascomús se ubicó muy por debajo de la misma. 
Tabla 11: Porcentaje de mujeres divorciadas (1947) y separadas/divorciadas (1960) sobre el total de la categoría en cada grupo de edad. Buenos Aires

\begin{tabular}{lrrrrrrrrr}
\hline & & \multicolumn{7}{c}{ Grupos de edad } \\
\cline { 3 - 10 } Año & Total & $15-19$ & $20-24$ & $25-29$ & $30-34$ & $35-39$ & $40-49$ & $50-59$ & 60 o + \\
\hline 1947 & 58.7 & 65.1 & 76.2 & 76.5 & 70.1 & 61.7 & 58.3 & 50.9 & 45.8 \\
1960 & 57.8 & 67.7 & 78.6 & 67.4 & 63.4 & 61.3 & 59.9 & 53.6 & 45.1 \\
\hline
\end{tabular}

Fuente: elaboración sobre la base de datos censales.

Al igual que en la provincia, las probabilidades comentadas crecieron escasamente hacia 1960: en La Plata, la medida fue de 11.7 por mil; en General San Martín fue de 9.1 por mil y en Chascomús fue de 7.7 por mil (Tabla 12).

Tabla 12: Probabilidad de estar divorciado (Pd) (1947) y separado (Ps), divorciado (Pd) y separado/divorciado (Ps,d) (1960) (por mil). Buenos Aires y partidos

\begin{tabular}{lcrrrr}
\hline Jurisdicción & Sexo & \multicolumn{1}{c}{1947} & \multicolumn{2}{c}{1960} \\
& & $\mathrm{P}(\mathrm{d})$ & $\mathrm{P}(\mathrm{s})$ & $\mathrm{P}(\mathrm{d})$ & $\mathrm{P}(\mathrm{s}, \mathrm{d})$ \\
\hline \multirow{4}{*}{ Buenos Aires } & Ambos & 7.2 & 8.0 & 1.1 & 9.0 \\
& Varón & 5.9 & 6.9 & 0.9 & 7.7 \\
& Mujer & 8.6 & 9.2 & 1.2 & 10.3 \\
& Ambos & 3.4 & 7.3 & 0.4 & 7.7 \\
Chascomús & Varón & 3.4 & 7.0 & 0.2 & 7.2 \\
& Mujer & 3.4 & 7.5 & 0.6 & 8.1 \\
General & Ambos & 10.2 & 8.0 & 1.2 & 9.1 \\
San Martín & Varón & 7.4 & 6.3 & 1.0 & 7.2 \\
& Mujer & 12.9 & 9.6 & 1.3 & 10.8 \\
& Ambos & 8.2 & 9.7 & 2.1 & 11.7 \\
La Plata & Varón & 6.1 & 7.1 & 1.7 & 8.7 \\
& Mujer & 10.3 & 12.1 & 2.5 & 14.5 \\
\hline
\end{tabular}

Fuente: Tablas $8 \mathrm{a}, 8 \mathrm{~b}, 8 \mathrm{c}, 8 \mathrm{~d}$.

Es importante destacar las peculiaridades de Chascomús pues exhibe las probabilidades más bajas lo que se podría interpretar como una expresión de un contexto conservador, inamovible en usos y costumbres a causa de la pequeña dimensión poblacional. Dicho de otro modo, en Chascomús los pequeños números retenidos por el censo de 1947 develan el contexto: 12 cristianos ortodoxos, 458 protestantes, 28 israelitas, 9 musulmanes, 13 matrimonios mixtos, 12 varones divorciados, 12 mujeres divorciadas, 42 
niños y 36 niñas nacidos fuera del matrimonio. Hacia 1960, Chascomús no parecía cambiar demasiado: 12 cristianos ortodoxos, 459 protestantes, 29 israelitas, 6 musulmanes, 197 unidos de hecho, 204 unidas de hecho, 36 varones separados/divorciados, 41 mujeres separadas/divorciadas, 32 niños y 33 niñas nacidos fuera del matrimonio (Anexo 1). ${ }^{19}$ En síntesis su pequeña dimensión poblacional, amén de su mayor ruralidad hacia 1947, descubre mecanismos de control social más personales.

Lo sugerente es que de dicho entorno emergió su máximo exponente, Raúl Alfonsín, quien siendo presidente impulsó la sanción de la ley de divorcio vincular 23505 en 1987. Resulta ilustrativo mencionar que el ex mandatario cursó sus estudios primarios en la Escuela Normal Regional de Chascomús, a la edad de 13 años ingresó al Liceo Militar General San Martín y se graduó como abogado en la Universidad Nacional de La Plata en 1950. A raíz del golpe militar de septiembre de 1955 que derrocó a Perón y proscribió al justicialismo, sufrió un corto periodo de prisión. Durante el gobierno de facto del general Juan Carlos Onganía, militó en la clandestinidad en favor de una corriente de opinión ética desfavorable a la soberbia castrense, lo que motivo su arresto en noviembre de 1966. Luego del fallecimiento del General Perón, cofundó la Asamblea Permanente por los Derechos Humanos.

\section{A MOdo de CIERRE}

Los resultados presentados en estas páginas parecen confirmar que la secularización "como hecho histórico tangible que no significa más que la separación de Iglesia y Estado, de religión y política" (Arendt, 2007: 282) no se había completado en la Argentina a mediados del siglo xx. Elemento que sintonizó con el desarrollo de una política demográfica que pretendió que la nupcialidad fuera la expresión de la política económica acuñada en el orden natural de las cosas.

Hay que mencionar que Llorens y Correa Ávila autores del texto Demografía Argentina. Esbozo de una política demográfica fueron voces más que autorizadas pues además de ejercer la docencia universitaria y ser parte de la elite de funcionarios estatales consultados tanto por el peronismo como por el ala castrense, contaban con el prestigio de ser miembros del Instituto Alejandro Bunge de Investigaciones Económicas y Sociales y de la Revista de Economía Argentina.

\footnotetext{
${ }^{19}$ Se agrega a la descripción el excedente de mujeres en unión que contradice la noción monogamica de las parejas: 58 casadas y 7 solteras en unión de hecho.
} 
En lo que hace al periodo enfocado en este estudio, los elementos de la política demográfica elaborada por los discípulos de Bunge, parecen haber ejercido cierta influencia mediante la acción del Secretario Técnico de la Presidencia José Figuerola — quien participó como jefe de gabinete del ministerio de trabajo del gobierno dictatorial del general Miguel Primo Rivera en España en el decenio de 1920 (Biernat, 2007:66). Sin embargo, se advierte su disconformismo con el curso que estaban tomando las cosas pues se referían al tema población en tanto "problema" aludiendo, con ello, a la ampliación de los derechos civiles de mujeres, niños y de los sectores sociales subalternos (Santana, 2010). Es por eso que buscaron incidir en el primer plan quinquenal de gobierno 1941-51 mediante el cruce de sus relaciones de poder y de saber, aunque esto no logró detener la ampliación de los derechos civiles durante el peronismo.

No obstante, sin duda, lograron incidir durante el primer periodo peronista, en la esfera de la política demográfica oficial exaltando "la dignidad de la mujer como esposa y como madre" pues ubicando, natural y funcionalmente, al hombre y a la mujer en el seno de la familia aumentarían los nacimientos. Es decir, para los discípulos de Bunge las medidas que preservarían al Estado del desorden social, del concepto materialista de la vida y del comunismo no debían propender a la ampliación de derechos civiles comentados en estas páginas pues en dicha ampliación residía la amenaza. Es cierto que el plan económico que favoreció con más del 50 por ciento del ingreso per cápita a los trabajadores (MJSDH/SDH/ANM, 2008: 26) produjo un importante impacto en el sector más joven de la población económicamente activa que es, al mismo tiempo, la población en edad núbil. Al punto que miembros de la elite de funcionarios estatales postulaban, científicamente, la necesidad de incrementar los casamientos reforzando la punición de la indisolubilidad del matrimonio, de la bastardía y de la ilegitimidad, y recomendaban crear dificultades en términos económicos a la soltería.

Estos elementos punitivos de la política pueden identificarse en escritos de época pues se alude a que quienes se divorciaban vivían en "una atmósfera de desconcepto e inmoralidad, equivalente, o superior, a la que pesa sobre una infidelidad conyugal discreta" además de ser un estigma para los hijos que eran "descalificados, como ilegítimos" (Ingenieros, 1953: 174). Se ha mencionado la obra El divorcio, cáncer de la sociedad y Biernat (2013: 21) ha identificado al divorcio como uno de los factores que se consideraba incidía en el descenso de la natalidad "al igual que la sodomía y el onanismo" lo que era visto con preocupación. Rodríguez Molas (1984: 
121-122) alude a la sanción que recayó sobre los hijos de Ángela González Alzaga de Ledesma quienes, en manos de las autoridades del colegio religioso La Asunción, fueron expulsados debido a que su madre había obtenido el divorcio absoluto durante los primeros meses de 1955 y la tenencia de los hijos de su primer matrimonio (Masciadri, 2007).

Ciertamente, el matrimonio indisoluble era visto como una de las piezas fundamentales del dispositivo. Al punto que la probabilidad de estar divorciado en 1947 o en 1960 fue muy baja en todas las unidades geográficas consideradas. En efecto, "el término dispositivo nombra aquello en lo que y por lo que se realiza una pura actividad de gobierno sin el medio fundado en el ser. Es por eso que los dispositivos deben siempre implicar un proceso de subjetivación, deben producir un sujeto" (Agamben, 2011: 256).

Según afirma Barrancos (2007:188), "las buenas marcas de nacimiento" eran exigidas por la sociedad y tanto Eva Duarte como Juan Perón "habían sentido en carne propia el menoscabo y la humillación" pues portaban una filiación inadecuada. Aunque también alude a que el ensañamiento fue mayor con ella, por su condición de mujer, y esta expresión ilumina un aspecto singular de las estadísticas. Mientras la ideología censal se negó a computar las "uniones ilegítimas" hasta el año 1960 pues dañaban la imagen de la nación, las estadísticas vitales identificaban, con alarma, la cifra de los nacimientos de "ilegítimos" diferenciando su sexo.

Elementos que parecen confirmar la tesis de Torrado (2003: 302) en cuanto a que, la integración social fue débil en la sociedad que emergió luego de la organización nacional puesto que los matrimonios fueron mayormente endogámicos. La autora apunta que la integración étnica se logró mediante la acción de "la escuela primaria, obligatoria, pública, gratuita y laica" que aseguró una "aculturación básica común". Por su parte, el texto redactado por Llorens y Correa Ávila (1948: 74) establece que la educación en liceos y escuelas normales debía portar el sello de la "educación para la vida familiar" donde la mujer/niña debía recibir instrucción para: el cuidado del hogar, la crianza y educación de los hijos, y la administración de la economía familiar. Es decir, el modelo de matrimonio que portaron los inmigrantes y el que instruía la escuela era el mismo.

Se ha visto que las cifras que acompañan la discusión no siempre respondieron a las exigencias de la política demográfica esbozada por los discípulos de Bunge. Hacia 1947, existía en Buenos Aires una elevada proporción de solteros pues el desbalance numérico fue importante cuando la Argentina recibía a las últimas oleadas de inmigrantes europeos. Al mismo tiempo, los índices de masculinidad de la población rural de Chascomús y 
La Plata muestran que el desbalance fue mayor de acuerdo con la generación y la coyuntura incidiendo en la soltería. La tasa bruta de nupcialidad caía constantemente, aumentaban los matrimonios entre nativos debido al efecto stock - mientras más grande es un grupo, mayor es su tasa de endogamia (Devoto, 2004: 332) — al tiempo que, hacia 1960, no hubo más remedio que censar las uniones consensuales ya que los nacimientos fuera del matrimonio, propios de las clases subalternas, no exhibían la tendencia desfavorable deseada por los redactores de la política demográfica examinada, antiguos miembros de la elite de funcionarios estatales que hacia 1943 asesoraban al gobierno militar de turno y que intervinieron también durante la primera etapa del gobierno peronista. Este grupo no vio con buenos ojos la cifra de 52501 personas divorciadas, la mayoría mujeres, que arrojó el censo de 1947, y vio con espanto la aprobación del divorcio vincular que respondía a los síntomas de la descomposición social y al resquebrajamiento del orden natural. Para ellos, la única solución posible fue recurrir al golpe palaciego e iniciar una política estatal convincente que disciplinara a las clases subalternas de manera definitiva. 
La nupcialidad en Buenos Aires a mediados del siglo XX: Chascomús, La Plata y San Martín / V. MASCIADRI

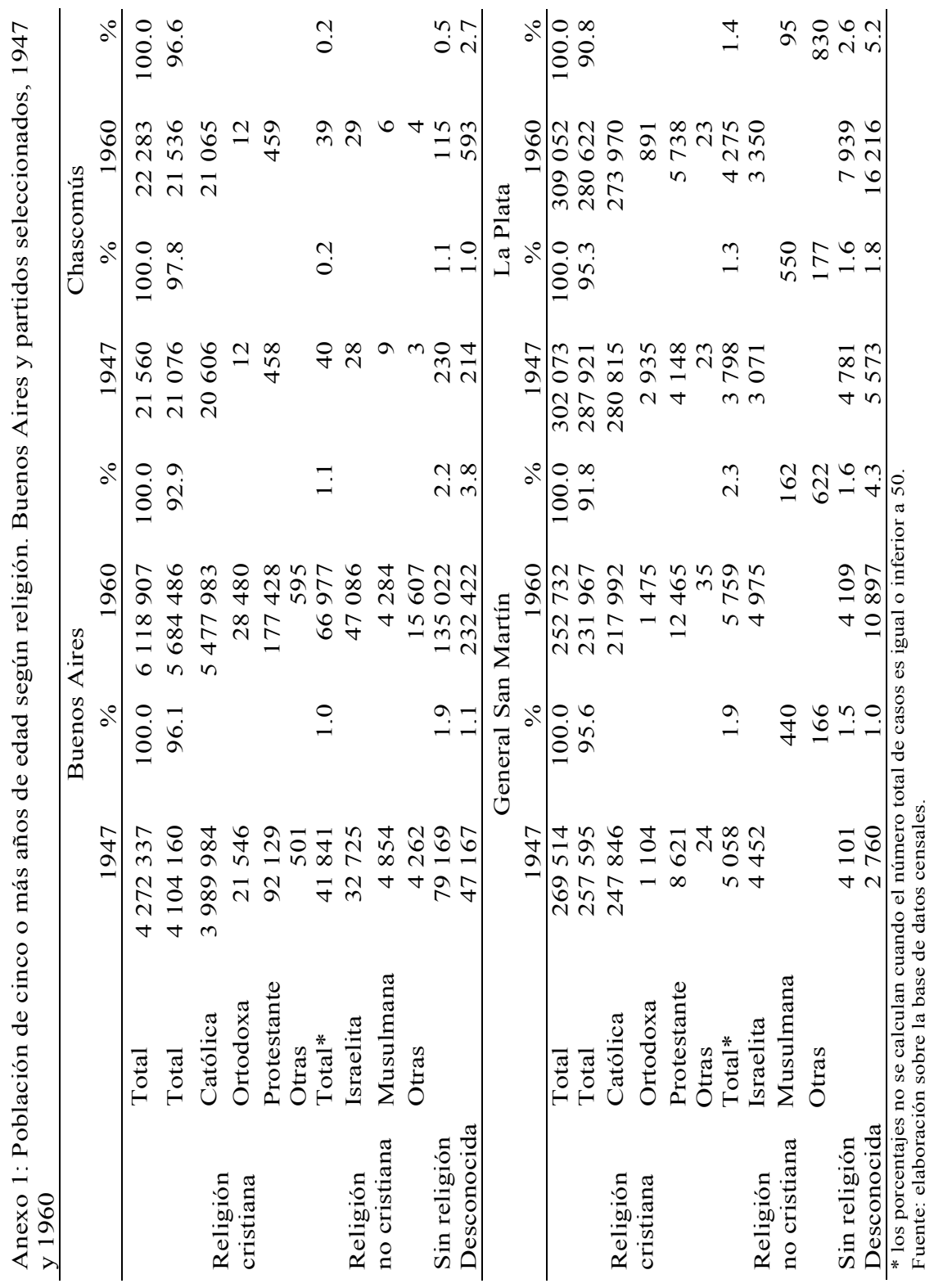




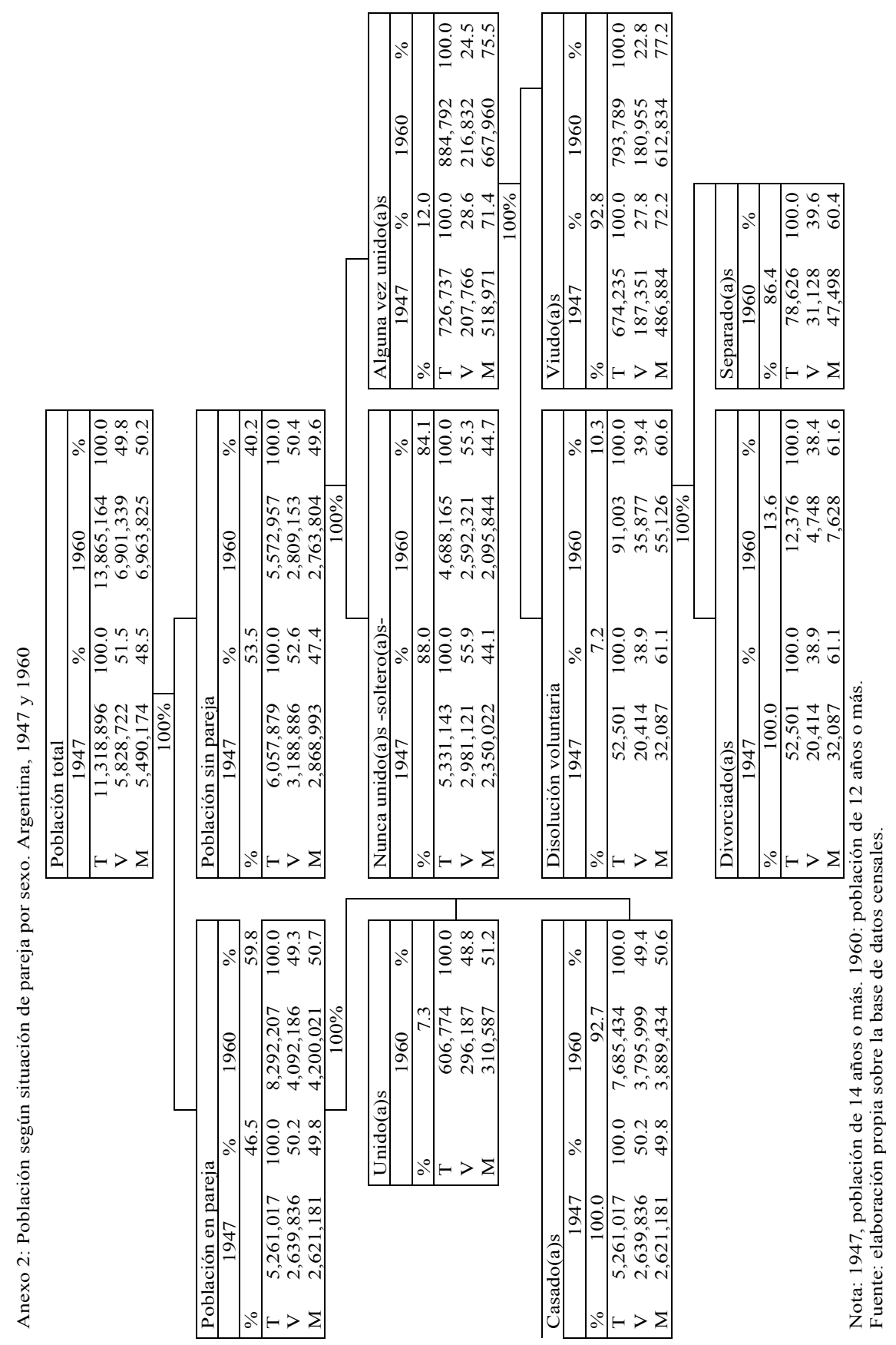




\section{REFERENCIAS BIBLIOGRÁFICAS}

Agamben, G., 2011, “QQué es un dispositivo?” En Sociología, año 26, 73: 249264.

Alcántara, E., 1983, "Estabilidad conyugal y patrones de cambio de estado marital", en Simmons, A., Conning, A. y Villa, M. (eds.), El contexto social de cambio de la fecundidad en América Latina Rural: aspectos metodológicos y resultados empíricos. CIID/CELADE. Canadá.

Arendt, H., 2007, La condición humana. Paidos. Buenos Aires.

Arendt, H., 2008, Sobre la revolución. Alianza Editorial. Buenos Aires.

Barrancos, D., 2007, Mujeres en la sociedad argentina. Una historia de cinco siglos. Sudamericana. Buenos Aires.

Bernetti, J. y Puiggrós, A., 1993, “De la guerra a la pedagogía (1943-1949)”, en Puiggrós, A. (dir.), Peronismo: cultura política y educación (1945-1955), pp. 1570, Galerna. Buenos Aires.

Biernat, C., 2007, ¿Buenos o útiles?: la politica inmigratoria del peronismo, Biblos. Buenos Aires.

Biernat, C., 2013, "Debates de ideas en torno a la protección materno-infantil durante el primer peronismo", en Revista Estudios ISHiR, año 3, núm. 7, pp. 5-25.

Bourgeois-Pichat, J., 1985, Nuevas fronteras de la demografía, CELADE. Santiago de Chile.

Bunge, A., 1984, Una nueva Argentina, Madrid, Hyspamérica Ediciones Argentina.

Cacopardo, M. C., 1996, "El reconocimiento del estado conyugal de la población”, en Aspectos teóricos y metodológicos relativos al diseño conceptual de la cédula censal, pp. 355-368. Serie D, núm. 2, vol. 2. Instituto Nacional de Estadísticas y Censos. Buenos Aires.

Céspedes, C. y Robles, C., 2016, Niñas y adolescentes en América Latina y el Caribe. Deudas de igualdad. Santiago de Chile, Cepal, UNICEF, publicación de las Naciones Unidas.

Ceva, M., 2012, "El ciclo de la inmigración”, en Otero, H. (dir.) Historia de la provincia de Buenos Aires: tomo 1. Población, ambiente y territorio, pp. 309-336, Edhasa. Buenos Aires.

Cicchelli-Pugeault, C. y Cicchelli, V., 1999, Las teorías sociológicas de la familia. Nueva Visión. Buenos Aires.

Comisión de Códigos, 1926, Estadísticas de juicios de divorcio en la Argentina. Senado de la Nación, H. Cámara de Diputados. Buenos Aires.

Cosse, I., 2006, Estigmas de nacimiento. Peronismo y orden familiar, Fondo de Cultura Económica. Buenos Aires. 
Devoto, F., 2004, Historia de la inmigración en la Argentina, Sudamericana. Buenos Aires.

Domingo, A., 1997, "La formación de la familia en tiempo de crisis. Madrid y Barcelona, 1975-1995", Tesis doctoral, Universidad Nacional de Educación a Distancia, Facultad de Ciencias Políticas y Sociología, Departamento de Sociología.

Elias, N., 1998, "El cambiante equilibrio de poder entre los sexos. Un estudio sociológico procesual: el ejemplo del antiguo Estado romano", en Elias, N., La civilización de los padres y otros ensayos, Santa Fe de Bogotá.

Elias, N., 2009, Los alemanes, Nueva Trilce. Buenos Aires.

Finchelstein, F., 2010, Fascismo trasatlántico: ideología, violencia y sacralidad en Argentina y en Italia, 1919-1945, Fondo de Cultura Económica. Buenos Aires.

Germani, G., 1987, Estructura social de la Argentina. Análisis estadístico, Ediciones Solar. Buenos Aires.

Giordano, V., Ramacciotti, K., Valobra, A., 2015, Contigo ni pan ni cebolla. Debates y prácticas sobre el divorcio vincular en Argentina, 1932-1968, Biblos. Buenos Aires.

Gonnard, R., 1972, Historia de las doctrinas de la población, CELADE. Santiago de Chile.

González Bollo, H., 2004, "La formación intelectual del ingeniero Alejandro Ernesto Bunge (1880-1913)", en Revista Valores en la Sociedad Industrial, año 22, núm. 59, pp. 36-43.

González Bollo, H., 2010, "Retomando la rutina perdida: la Dirección Nacional de Investigaciones, Estadística y Censos (1946-1949)", en Segundo Congreso de Estudios sobre el Peronismo (1943-1976), Universidad Tres de Febrero, 4-6 noviembre.

Ingenieros, J., 1953, Tratado del amor, Ediciones Meridion. Buenos Aires.

IUSSP y CELADE, 1982, Diccionario demográfico multilingüe. Internacional Union for the Scientific Study of Population, Centro Latinoamericano de Demografía, Bélgica.

Jelin, E., 1989, "El celibato, la soledad y la autonomía personal: elección personal y restricciones sociales", en Estudios Demográficos y Urbanos, vol. 4, núm. 1, pp. 117-138.

Llorens, E. y C. Correa Ávila, 1948, Demografía argentina. Esbozo de una política demográfica. Facultad de Ciencias Económicas, Universidad Nacional de Buenos Aires. Buenos Aires.

Masciadri, V., 2002, "Tendencias recientes en la constitución y disolución de las uniones en Argentina”, en Notas de Población, año 29, núm. 74, pp. 53-109.

Masciadri, V., 2006, "Hechos demográficos asociados a la nupcialidad: panorama latinoamericano reciente", en Celton, D., Ghirardi, M. y Peláez, E. (eds.), El nexo 
entre Ciencias Sociales y Politicas: migración, familia y envejecimiento, pp. 671722, UNESCO, UNC. Córdoba.

Masciadri, V., 2007, “Tendencias en la constitución y disolución de las uniones en la Argentina (1947-2001)”, tesis de doctorado en Demografía, Universidad Nacional de Córdoba, inédita. Córdoba.

Masciadri, V., 2012a, "Consideraciones en torno a las implicaciones de dos problemas lógico-conceptuales en los estudios sobre nupcialidad en las últimas cinco décadas", en Estudios demográficos y urbanos, vol. 27, núm. 3, pp. 789-838.

Masciadri, V., 2012b, “¿Transmisión intergeneracional del divorcio? Tensiones epistemológicas entre disciplinas de confluencia", en Papeles de Población, vol. 18, núm. 74, pp. 57-86, Universidad Autónoma del Estado de México Toluca, México.

Masciadri, V., 2013, Constitución y disolución de parejas en la Argentina (19472001), Biblos. Buenos Aires.

Masciadri, V., 2016a, "Bando, geografía y niñez en Argentina (1966-1983)", en La Colmena, 89, pp. 67-91 ISSN 1405-6313.

Masciadri, V., 2016b, Estadísticas militares y sistemas de datos conexos: una exploración, mimeo.

MJSDH, SDH y ANM, 2008, De la Ley de Residencia al Terrorismo de Estado. La actividad represiva del Estado ante los movimientos sociales emergentes durante el siglo XX, Ministerio de Justicia, Seguridad y Derechos Humanos; Secretaría de Derechos Humanos; Archivo Nacional de la Memoria, Buenos Aires.

Moreno, J. L., 2007, “El desafío historiográfico de la ilegalidad”, en Torrado, S. (comp.) Población y bienestar en la Argentina del primer al segundo Centenario, pp. 501-527, Edhasa. Buenos Aires.

Otero, H., 2006, Estadística y Nación. Una historia conceptual del pensamiento censal de la Argentina moderna 1869-1914, Prometeo libros. Buenos Aires.

Otero, H., 2007, “Censos antiguos: 1869, 1895, 1914, 1947”, en Torrado, S. (comp.) Población y bienestar en la Argentina del primer al segundo Centenario. (pp.187-213), Edhasa. Buenos Aires.

Pantelides, E., 1984, Análisis y propuesta de corrección de la información sobre estado civil en los cuatro primeros censos nacionales argentinos, Serie Estadísticas Sociodemográficas, CENEP. Buenos Aires.

Pontoriero, E. y Franco, M., 2013, “Decreto secreto del Plan Conintes (1958)”, en Anuario. Lucha Armada en la Argentina, 9:112-117.

Pressat, R., 1983, El análisis demográfico. Métodos, resultados, aplicaciones. Fondo de Cultura Económica. México.

Rodríguez Molas, R., 1984, Divorcio y familia tradicional, Centro Editor de América Latina. Buenos Aires.

Santana, R., 2010, Santoro: realidad, sueño, elegía, Caseros, UNTREF. 
Somoza, J., 1971, La mortalidad en la Argentina entre 1869 y 1960, Centro de Investigaciones Sociales, Instituto Torcuato Di Tella, CELADE, Del Instinto Editorial. Buenos Aires.

Torrado, S., 1993, Procreación en la Argentina. Hechos e ideas, Centro de Estudios de la Mujer, La Flor. Buenos Aires.

Torrado, S., 2003, Historia de la familia en la Argentina moderna (1870-2000), La Flor. Buenos Aires.

Valobra, A. y Giordano, V., 2013, "Absolute divorce in Argentina, 1954-1956. Debate and practice regarding a short-lived law", en The history of the family, DOI: $10.1080 / 1081602 X .2012 .753848$.

Vetta, A. y Courgeau, D., 2003, "Demographic behaviour and behaviour genetics", en Population, vol. 58, núms. 4-5.

Villalta, C., 2012, Entrega y secuestros. El rol del Estado en la apropiación de niños, Del Puerto, Centro de Estudios Legales y Sociales, Ciudad de Buenos Aires.

\section{INFORMACIÓN CURRICULAR DE LA AUTORA}

\section{Viviana Masciadri}

Es psicóloga, doctora en Demografía por la Universidad Nacional de Córdoba y magister en Demografía por la Universidad Autónoma de Barcelona. Actualmente se desempeña como investigadora adjunta en la Carrera de Investigador Científico en el Consejo Nacional de Investigaciones Científicas y Técnicas con sede en el Instituto Interdisciplinario de Estudios de Género, Universidad de Buenos Aires, Argentina.

Dirección electrónica: v.masciadri@gmail.com

Artículo recibido el 8 de enero de 2016 y aprobado el 4 de abril de 2017. 